Portland State University

PDXScholar

Summer 8-20-2019

\title{
The Tangle of Institutional Care and Control at a Shelter for Commercially Sexually Exploited Youth
}

Liat Tzvia Mayer

Portland State University

Follow this and additional works at: https://pdxscholar.library.pdx.edu/open_access_etds

Part of the Anthropology Commons

Let us know how access to this document benefits you.

\section{Recommended Citation}

Mayer, Liat Tzvia, "The Tangle of Institutional Care and Control at a Shelter for Commercially Sexually Exploited Youth" (2019). Dissertations and Theses. Paper 5276.

https://doi.org/10.15760/etd.7149

This Thesis is brought to you for free and open access. It has been accepted for inclusion in Dissertations and Theses by an authorized administrator of PDXScholar. Please contact us if we can make this document more accessible: pdxscholar@pdx.edu. 
The Tangle of Institutional Care and Control at a Shelter for Commercially Sexually Exploited Youth

by

Liat Tzvia Mayer

A thesis submitted in partial fulfillment of the requirements for the degree of

Master of Arts

in

Anthropology

Thesis Committee:

Michele Gamburd, Chair

Charles Klein

Mrinalini Tankha

Portland State University

2019 
(C) 2019 Liat Tzvia Mayer 


\begin{abstract}
My cultural anthropology master's thesis focuses on the workings of Inanna House, an emergency shelter/residential program for commercially sexually exploited (CSEC) youth in Portland, Oregon. In the summer of 2017, I did participant observation and interviewed youth and direct care staff members at the CSEC shelter I had been working at for 2 years. I begin by situating ideas about domestic minor sex trafficking (DMST) within larger historical, legal, economic, and political contexts. I consider concepts of childhood, race, class, gender, and sexuality on the story of DMST in the United States.
\end{abstract}

Next, I explore the ways humans and institutions move around, and sometimes through, a shared human vulnerability. By considering the functions of trauma and CSE youths' experiences of resilience and relationship, I make a case for care based on interconnectedness. Using the lens of commensurability and social commensurability, I highlight how care oscillated between a disciplinary gaze and a deep relatability (Povinelli 2001; Garcia 2010). Further, I discuss how rules meant to consider trauma's impact on the mind and body of youth often faltered with inconsistency, forming traumatropisms instead of trauma-informed care (Feldman 2015). I draw out the evidence for the tangle of care and control in the shelter.

In addition, I examine youth and staff experiences of living and working at Inanna House. I focus on how Inanna House used techniques of quasi-total institutions and disciplinary power along with tools of trauma-informed care to structure its program, and 
how all three often fell apart (Goffman 1969; Foucault 1976). In the cracks of the crumbling foundational structures though, I bring into view instances of what I call 'becoming' (Deleuze 1997). Becoming refers to the ways both youth and staff disrupted roles based on discipline and control or being trauma-informed, and were more malleable, more desiring, and more unknown than the structures around them accounted for (Biehl and Locke 2017).

Finally, I discuss the role of grief, often missing in the organization of care in institutions like Inanna House, as well as in the anthropology of violence working on identities and relations in the aftermath. I try through this thesis to express the complexities and connections, the messiness and tenderness, running through the relationships and institution of a shelter for commercially sexually exploited youth. 


\section{Dedication}

I would like to dedicate this thesis to the tenacious and brazen youth and staff at Inanna House. May they continue to fill the world with fierce light and colorful laughter.

I would also like to dedicate this work to my father. In his passing I was truly given the gift of grief; may his memory forever be a blessing. 


\section{Acknowledgements}

First, I would like to give thanks to the hill behind my house along the Clackamas River. The entirety of my graduate studies, work at Inanna House, and writing of this thesis happened while I lived under the protection of this hill. My relationship with the dappled wooded space of the hill the past many years gave me sustenance, fortitude, and serenity that were absolutely fundamental to this project of being. It was the spring at the top of the hill that taught me how to sit with and honor grief, honor the sacred labor of creation, and honor the becoming that was unfolding. I want my thanks to go first to this place.

The web that supports me also includes many friends who catch me with soft hands when I struggle and especially my partner, Blaine, for continually teaching me about unconditional love, my faery godmother, Louisa, for her wisdom, my sister, Yonat, for sharing this journey with me in so many ways, and my mother, Gigi, for teaching me how to receive love and selflessly give it, with grace.

I would also like to thank my advisor, Michele Gamburd, for pushing me and believing in me to the very end, and my teacher Charles Klein for opening doors into an anthropology becoming. 


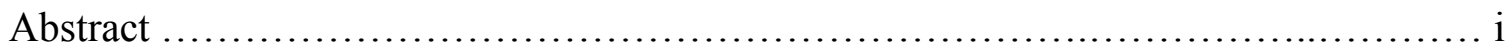

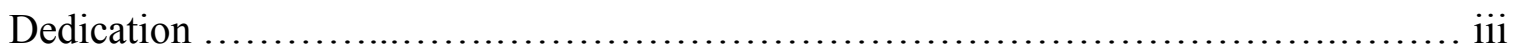

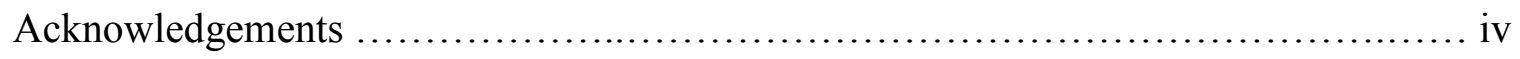

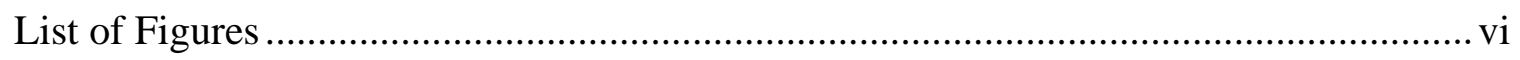

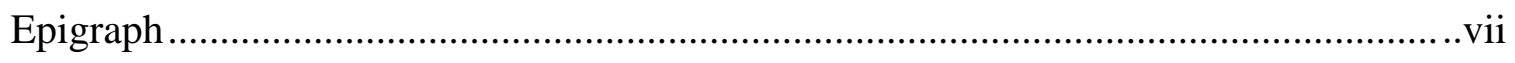

Chapter 1

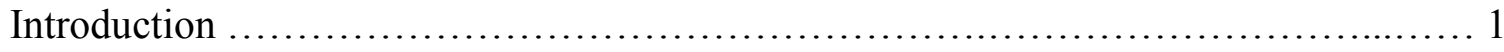

Chapter 2

A Continuum of Violence ................................................... 26

Chapter 3

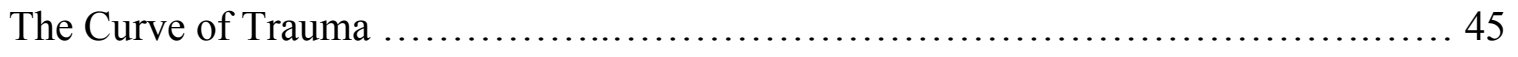

Chapter 4

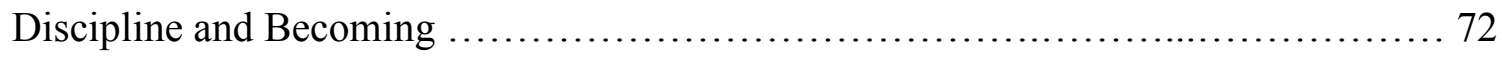

Chapter 5

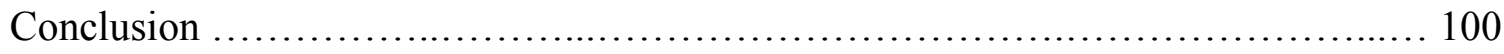

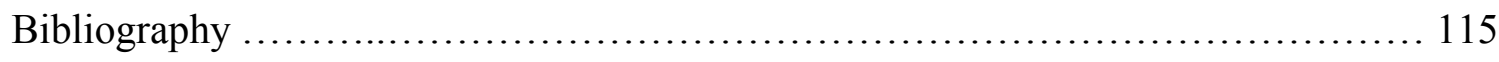

Appendix A. Multnomah County CSEC Protocol ............................ 124 


\section{List of Figures}

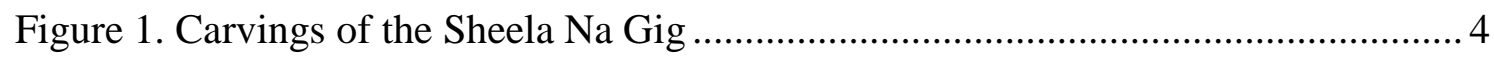


"The wound is part of a passage, not the end in itself." (Shaw 2019) 


\section{CHAPTER 1: Introduction}

It is the hour of petals falling.

Listen hard to the flower blooming in reverse.

We are losing parts of ourselves

we did not know. It is not spring, yet

everything is being born uncontrollably.

\section{$\underline{\text { Doorways }}$}

One evening at Inanna House, an emergency shelter and long-term residential program for commercially sexually exploited (CSE) youth, a 15 year-old mixed race girl named Simone asked if I would sit in the doorway of her bedroom while she fell asleep. She found it hard to fall asleep alone.

That Simone knew what she needed to help her sleep and was able to ask for it impressed me. Something in Simone's familiarity with Inanna House allowed her to make this tender request. Simone had accessed services at Inanna House many times in the prior two years; each time she did, she came to know that staff members would be present to offer her support. Simone's request that evening revealed to me her vulnerability and her recognition of needing others, even for the fundamental experience of sleep. Her request reflected trauma, regulation, and the interpersonal realm, as well as her strength, maturity, capableness, and resilience.

Inanna House was filled with moments like these, of vulnerability, trust, and the tensions of the in-between: waking and sleep, day and night, residents and staff members, 
surviving and survivor. I got a book for myself to read and sat with my back against the doorframe while Simone settled into sleep.

\section{$\underline{\text { Sheela Na Gig }}$}

My cultural anthropology master's thesis focuses on the workings of Inanna House, a shelter for commercially sexually exploited (CSEC) youth in Portland, Oregon. In the summer of 2017, I did participant observation and interviewed direct care staff members and youth at the CSEC shelter/residential program I had been working at for 2 years. I begin the thesis by situating concepts of childhood and domestic minor sex trafficking (DMST) within larger historical, legal, economic, and political contexts. I then discuss how the shelter design approached care both through a disciplining gaze and through a deep relatability. I develop an understanding of this hybrid design through a consideration of trauma and a discussion of commensurability (gaze) and social commensurability (relatability). Further, my research highlights how using traumainformed care in the controlled environment of a quasi-total institution left both staff members and youth frustrated and confused. To get around difficulties that arose, youth and direct care staff used creative ways to relate to each other. Youth at times strategically used a bidirectional gaze and staff members at times oriented to the youth through what I call 'becoming,' that is, oriented to the desire, plasticity, and unfinishedness of youth, (Deleuze 1997; Biehl and Locke 2017). Finally, I consider grief as a productive tool both for care providers and individuals navigating trauma and systems of care, as well as anthropologists working on identities and relations in the aftermath of violence. 
In many ways, I see the experiences and lives of youth affected by commercial sexual exploitation breaking open rigid conceptions of childhood, agency, consent, sexuality, gender, and power. I see a shelter for commercially sexually exploited youth complicating concepts of care, control, protection, trauma, and belonging.

To understand how "commercially sexually exploited children" (CSEC) or "domestic minor sex trafficking" (DMST) became terms to refer to populations whose members have become delineated under the eyes of the law, I will discuss the contemporary large-scale rules set by the United Nations protocols and US Acts defining human trafficking. Beside the definitions of trafficking by these large entities, though, activists, community groups, and NGOs sometimes define youth involved in sexual exchange differently. Some of these groups advocate for language that emphasizes the labor of sex work above the victimhood of sex workers (Chateauvert 2014; Smith and Mac 2018). Programming that aligns with this perspective minimizes labeling youth as exploited or services as designed for victims of domestic minor sex trafficking, stressing instead phrases like 'trading sex' for money, housing, or other needs. In this thesis I predominantly use 'commercially sexually exploited youth' to refer to the residents of Inanna House because that is the terminology the program and agency used, and also the terminology youth associated with the shelter.

The complexity and dynamics of contemporary domestic minor sex trafficking in the United States echo the challenge made by carvings of the Sheela Na Gig (see Figure 1. below). Predominately found in Ireland on Medieval churches as cornerstones or above entryways, the Sheela Na Gig depicts a woman holding open her vulva, with a face at times menacing, stunned, or smiling (Goode 2016). Her placement, in time and space, 
breaks open a brittle understanding of the past. A naked woman on a church complicates a dominant historical perspective that narrowly views the lives of Medieval women and their relationship to their bodies and their sexuality. The Sheela Na Gig places the female body and different aspects of the feminine, hag and goddess, smack dab in the middle of the Medieval past. Domestic minor sex trafficking likewise brings to light historically situated perspectives on the bodies of women and children, along with ideas about the beautiful and the grotesque. People's responses to the Sheela Na Gig mirror their reactions to my research interests: shock, horror, and a change of subject.
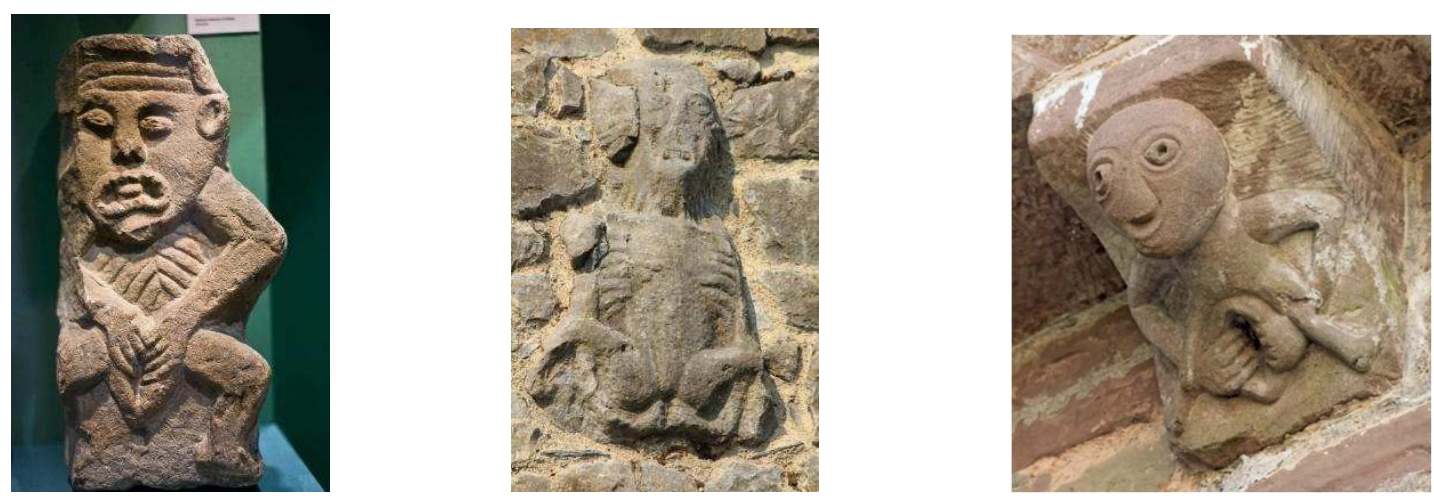

Figure 1. Carvings of the Sheela Na Gig, a woman holding open her vulva, her face menacing, stunned or smiling, used as building stones on Medieval churches. (Images Goode 2016)

A branch of leftist feminists and the Christian right wing collaborate on antitrafficking advocacy with the approach that domestic minor sex trafficking is out of place in contemporary time, calling to "End Modern Day Slavery." These anti-trafficking advocates use their rallying cry for people to come together, overcome political differences, and work toward a common cause. Much of this contemporary awareness and advocacy often overlooks historical and structural underpinnings to the framing of the idea of trafficking, a frame that merges trafficking with prostitution and prostitution with particular ideas about gender and race (Lerum 2012; Ringdal 2004). Further, claims 
about 'modern day slavery' are made in relation to the past despite scant reliable statistics about child prostitution because sexuality and prostitution have historically been considered part of a private sphere beyond the limits of jurisprudence until into the twentieth century (Gordon 2004; Pleck 1988). These odd bedfellows see eye to eye on an approach to sex trafficking that relies on increased policing, prosecution, and imprisonment to address violence in the domestic sphere. Sex work activists, on the other hand, commonly advocate for less police involvement and decriminalization, such as the Decrim NY coalition fighting to create the Stop Violence in the Sex Trades Act (Kadirgamar and Zen 2019).

As ideas about childhood change, new questions about youth sexuality arise. Are youth involved in sex work promiscuous offenders, naive victims, or resilient survivors? Or all three? Or none of the above? As the government shifts its views on its role to protect childhood and women, it shifts its definitions of who is worthy of protection, who is deserving of care, what kinds of rights to grant and to whom, and what is considered a greater crime - prostitution or exploitation.

Further, CSE youths' lives remain precarious and often land in liminal spaces of economic and political systems. Youth who are identified as commercially sexually exploited, and youth engaged in survival sex or sex work, find themselves on the social margins, abandoned by society in a variety of ways. When they come in contact with law enforcement, they are sometimes seen as victims and sometimes as offenders; punishment and protection get interwoven in this paradigm. Moreover, youth involved in sexual exchange often have complex trauma and a complex capacity for survival complicating diagnostic and treatment paradigms. 
This thesis explores how commercially sexually exploited youth belong to macro economic and political systems and how these youth belong to themselves and to the people in their lives. What does domestic minor sex trafficking tell us about our times?

What does it uncover and what does it carve a space for that otherwise remains unspoken about the state of our world, and more importantly, the breadth of human experience? Like the Sheela $\mathrm{Na}$ Gig, how do the lives of commercially sexually exploited youth form as blessing and warning on cornerstones of what some want to call the 'dark ages' of our time?

$\underline{\text { Inanna House }}$

I conducted research for this thesis at Inanna House (a pseudonym), which was both an emergency shelter for commercially sexually exploited youth between the ages of 14 and 21 and a residential program where youth could live for up to 18 months. To be considered 'commercially sexually exploited' and thus be eligible for shelter at Inanna House could mean many things. Mitchell et al. (2010) write, “A random sample of minor prostitution arrests found that most (57\%) involved a third-party exploiter, $31 \%$ involved no third-party exploiter, and the remaining 12\% involved familial exploitation (Gibbs et al 2015, 1)." Eligibility could include stripping, having a pimp and working on the street, having a manager and doing sex work through online platforms, online videos, and pornography. In addition, the US Department of Justice Office of Juvenile Justice and Delinquency Prevention (OJJDP) website states that

CSEC also includes situations where a child, whether or not at the direction of any other person, engages in sexual activity in exchange for anything of value, which includes non-monetary things such as food, shelter, drugs, or protection from any person (https://www.ojjdp.gov/programs/csec_program.html). 
The OJJDP notes that CSEC "is not legally defined by federal statute or case law. However, several federal criminal provisions can be applied to conduct that falls within this definition of CSEC." Youth who stayed for one night at the shelter along with youth who lived there for 6 months or a year all had a diverse array of experiences that brought them there.

Inanna House sat on a corner lot in a quiet area with a fenced yard not far from shops, restaurants, and public transit. For months, a large plastic garbage can, mostly empty, a quarter filled with water, and a broken bright pink folding bucket chair, sopping wet, sat along the walkway between the driveway and the front of the house. At the top of wooden stairs to the second story front door, a small porch sat off sliding glass doors with a table, plastic chairs, and a large ashtray; cigarette butts lay scattered on the ground below the slats of the porch. Youth returning from school, staff coming on for a shift, or service providers like advocates from the Sexual Assault Resource Center all required Inanna House staff members to let them in. For security reasons, only service providers and residents could know the address of the house. Waiting outside for a staff member to come open the door, a youth would announce loudly, "DOOR!" before someone arrived to unlock it.

Arriving at the house, one would enter into the upstairs living room where often youth sat on the large wrap around couch watching TV. The living room opened into the dining area with a very large dining table with an assortment of chairs. At the far end of the room sat two bookshelves and a computer between them. On the bookshelves were a disarray of crafts, games, magazines, books, and other odds and ends. The computer, when working, was rarely used because it had restricted internet access. Youth could only 
do limited searches; they could not check their email, engage with any social media, or use any type of messenger sites. The staff at Inanna House monitored and mediated youths' access to the outside world so that the secure location of the house was not revealed and so that youth did not continue to be involved with traffickers or organize to do sex work while staying at the house.

To the left of the living room, past a full bathroom, a hallway lead to three bedrooms and the kitchen. One of these bedrooms had been turned into the office. The office space went through occasional furniture reconfigurations, but it mostly remained a space not quite big enough to accommodate all that happened there. Youth often came into the office to hang out with staff. At times, two staff and three youth vied for space amidst two large desks, resident files, a locked cabinet with medicine, and extra bedding. Next to a small filing cabinet with lock boxes where youth stored their cigarettes or other small personal items, sat a staff computer and the monitor for the 6 security cameras situated outside and inside the house.

The kitchen, across from the office, remained relatively clean. The counters were usually wiped down but not scrubbed, the floor swept but not mopped. At the end of each shift, the staff cleaned up or let incoming staff members know which youth was responsible for a mess. The two bedrooms beside the office were designated for new clients. Because the program was voluntary, new clients often stayed for a few nights and then left. If they stayed longer, the program viewed a 21-day consecutive stay with strict limitations to the outside world as a first step in a process of change, providing a sort of detox from exploiters to help youth make a shift out of exploitation. After this 21 day consecutive stay, youth became eligible to move to a room downstairs. Living downstairs 
offered youth more privacy and independence by not being next door to the office where the staff spent a lot of time.

On the lower floor, at the bottom of the stairs, often a dirty towel or some clothes sat beside a washer and dryer. The living room space downstairs had a large corner desk and a large elliptical machine, rarely used except to store bags of give-away clothes or a few dirty dishes. The rest of the living room included a stand-up piano, a medium sized couch, two bean bag chairs, and a TV that did not work mounted on the wall. A computer monitor with Netflix access and a gaming system sat on a coffee table. The downstairs had five bedrooms along a long hallway and two more full bathrooms. The house felt lived in, but not necessarily cared for.

\section{Combating Sex Trafficking}

U.N. policies and US Acts attempt to suggest responses and solutions to sex trafficking. These solutions look to the formation of government task forces, interagency coordination, and the funding of non-governmental organizations. The year 2000 saw signed into law both the United Nations' Convention Against Transnational Organized

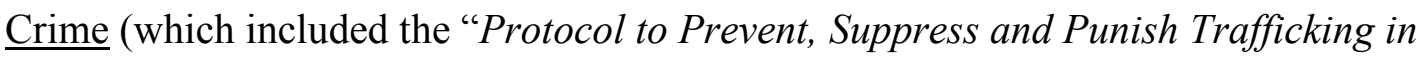
Persons, especially Women and Children") and the United States' Trafficking Victims Protection Act (TVPA). The "Protocol to Prevent, Suppress and Punish Trafficking in Persons, especially Women and Children," which became effective in December of 2003, was the "first global legally binding instrument with an agreed definition on trafficking in persons" ("United Nations Convention against Transnational Organized Crime" n.d.). The convention states, 
"Trafficking in persons" shall mean the recruitment, transportation, transfer, harbouring or receipt of persons, by means of the threat or use of force or other forms of coercion, of abduction, of fraud, of deception, of the abuse of power or of a position of vulnerability or of the giving or receiving of payments or benefits to achieve the consent of a person having control over another person, for the purpose of exploitation. Exploitation shall include, at a minimum, the exploitation of the prostitution of others or other forms of sexual exploitation, forced labour or services, slavery or practices similar to slavery, servitude or the removal of organs ("United Nations Convention against Transnational Organized Crime" n.d.).

By creating an international document clearly defining the terms of trafficking and exploitation, the United Nations established an avenue for shared ways of approaching the issues in criminal offence and victim services, as well as explicit ways to cooperate in regards to investigation and prosecution.

The United Nations definition of trafficking and exploitation centers the 'victim' and parallels the United States' Trafficking Victims Protection Act (TVPA) which also uses a victim centered response model. Broadly, the TVPA model includes the three 'P's: Prevention, Protection, and Prosecution. The TVPA includes a measure to assess how well a country is complying with the United States' anti-trafficking policies. Three tiers describe a given country's ability and interest in compliance. Countries falling into the third tier are subject to serious consequences, including sanctions on humanitarian and non-trade related aid (Goodey 2008). Both the UN protocol and US Act focus on protection above robust attempts at prevention or prosecution. A literature review done by the Office of Juvenile Justice and Delinquency Prevention highlighted how responding to the needs of trafficking victims is generally less complicated compared with trying to resolve the root causes of human trafficking, which often include unequal economies or conflicts and war (Goodey 2008; OJJDP 2014). 
The TVPA has been reauthorized five times. A particular focus on sex trafficking of minors was included when the TVPA was attached to the Violence Against Women

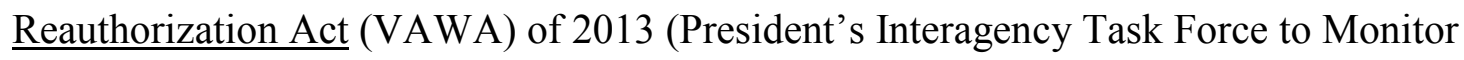
and Combat Trafficking in Persons 2014). Both the UN protocol and the TVPA have increased funding and awareness around trafficking issues.

State and then county governments administer US federal funding. The creation of anti-trafficking task forces, within the FBI and police departments across the country, have provided in-depth training for police to understand and identify victims and educate the public. Funding also helped to provide new services for victims, who had previously been viewed as offenders under the eyes of the law (Brennan 2014). Through contracts at the county level, nongovernmental agencies and non-profit organizations provide services for victims of domestic minor sex trafficking. These services form a network of similar forms of governmental care such as the care provided by the department of human services, juvenile detention, and foster care.

\section{$\underline{\text { An Inter-Agency Model }}$}

In Multnomah county, a sex trafficking task force coordinated an interagency model to address the complex needs of CSE youth in the area; see Appendix 1. This included a public-private partnership between the department of human services (DHS), the DHS juvenile services division, local law enforcement, and community partners, including Blue Sky Youth Programs, a pseudonym for the umbrella organization of Inanna House. 
Blue Sky Youth Programs began in 1972 providing residential care for youth struggling with homelessness and drug abuse. It grew to operating more than 40 programs and serving 6,000 youth and families each year. Programs range from homeless, runaway, residential and re-entry services for youth, as well as teen parenting, community food, and education scholarship programs. Blue Sky Youth Programs' philosophy focuses on community partnership, collaboration, and innovation using strength-based, harm reduction, positive youth development, and a trauma-informed toolkit. 91\% of funds for Blue Sky's Programs come from contract service fees. The nonprofit organization is independently audited and run by a volunteer board of directors.

As part of Blue Sky's runaway youth services, it oversees the Juvenile Reception Center (JRC), a juvenile detention alternatives initiative, as well as Inanna House. The JRC provides a non-secure setting for youth aged 11 to 17 when picked up by Portland Police for truancy, curfew violations, running away, trespassing, and other low level misdemeanors offenses. This included police arrest for prostitution or police placing a youth in protective custody because of concern a youth was being trafficked.

Once a youth was in custody, law enforcement would contact the Sexual Assault Resource Center for an advocate to accompany the youth to a meeting at the JRC with a multi-disciplinary team to assess next steps. The multi-disciplinary team could include DHS, guardians, the case manager of Inanna House, and other non-profit organization's care providers. Treatment plans ranged from youth returning home/foster placements, voluntarily going to Inanna House, or referred for hospitalization or subacute care depending on their mental and physical condition. The one other residential facility in Multnomah county for commercially sexually exploited youth was a secure court 
mandated facility many youth at Inanna House had been to at one point or another in their lives. Youth could also be referred to Inanna House by social workers, case managers, or simply by walking into the intake center and being screened for meeting with a CSEC multi-disciplinary team as described above.

The Multnomah County interagency model used recommended best practices by addressing services and supports for safety; physical and emotional well-being; connections to services, peers, family and community; and resources for self-sufficiency (Gibbs et al 2015). As one part of the interagency model, Inanna House offered food, shelter, case management, and therapy to youth who self disclosed to a service provider that they were currently or previously commercially sexually exploited. Other associated organizations offered education, life skills, employment training, and medical care. In addition, in "Finding a Path to Recovery: Residential Facilities for Minor Victims of Domestic Sex Trafficking,” Clawson and Grace (2007) discuss prioritizing hiring survivors as staff with an authentic understanding of "The Life" (street slang for prostitution) and therefore a natural ability to connect with CSE youth. Survivor mentoring may offer more opportunities for connection and opening up by the youth. Blue Sky Youth Programs sought to hire survivors of trafficking or former sex workers when it opened Inanna House and at the time of my research half the staff employed identified in this way.

As residents in a voluntary program, youth could leave Inanna House whenever they wanted. After a 24-hour absence, they could choose to return at any time and go through a process of re-entry. If they did leave, though, the law required staff members to file a "run report" with the police informing them that an underage youth had run away. 
Staff members were to report to police what time a youth left, in which general direction, and give a description of the youth's clothing. As I will discuss further in Chapter 3, youths' entrances to and exits from Inanna House often came through interactions with law enforcement.

\section{Complex Care}

Inanna House came into existence as a separate shelter from other homeless and runaway youth shelters that already existed in the Portland metro area because of the specific complexity of CSE youths' trauma and their correlating complex strategies for survival. Though relatively little research exists on best practices regarding services for CSE youth (and even less so when the shelter opened in 2011), recommendations from the handful of examples of shelters working with sex trafficked youth nationwide urged separate shelters for CSE youth (Ferguson 2009). This theoretically allows a traumainformed care approach that can develop specialization in the needs of complex trauma survivors. Inanna House included accommodating policies that made services more accessible to youth who may be considerably more resistant and more reactive to rules and authority because of their experience of violence and coercion. Their experiences in 'The Life' also made them more resourceful and more independent, further requiring unique specialization in services.

CSE youths' needs are considered complex in part due to complex trauma. Complex trauma refers to trauma "that is developmental in nature, meaning that traumatic experiences are repetitive and additive, typically occurring over a period of time, and taking place in relational contexts that are influential to the victim's 
development" (Jaffe et al 2018, 14). Complex trauma can manifest in a variety of ways. Due to the impact of trauma on the nervous system and the brain, CSE youth may have to negotiate difficulty sleeping, somatic complaints like stomach aches, anxiety, dissociation, paranoia, anger, and difficulty with time management. They may contend with severe depression, thoughts of suicide, and feelings of deep shame. The combination of complex trauma and the complicated affects that it can have on the physiology, cognition, and emotions of a person can produce someone who does not easily fit a stereotype. Megan Conti writes, "Working with patients whose understanding of themselves and their life experiences embody this type of resistance to essentialism requires closer attention to their process of meaning making and the culturally informed embodiment of their experience" (Conti 2018, 15). In this thesis I will discuss Inanna House's challenges establishing services that handled these complex needs.

Added to this diagnostic definition of complex trauma are the larger structural factors that contribute significantly to many CSE youths' daily traumatization and polyvictimization. One youth spoke to this in her interview by saying, "So just lookin at statistics, it's like, you could be a great staff and know a lot of things but as far as like, growing up black, you'll never understand that, so you can never relate to me." Many CSE youth experienced trauma due to marginalization and discrimination because of class, sexuality, and race. Youth from marginalized communities had to negotiate the ways in which sociocultural contexts augment interpersonal traumatic events such as childhood abuse and domestic violence and how complex trauma includes experiences of oppressive social structures as everyday occurrences (Quiros and Berger 2013, 4). Although I recognize the vital importance of race and class in understanding youths' 
experiences of commercial sexual exploitation, I do not explore these issues in depth in this thesis.

\section{$\underline{\text { Trauma Informed Care }}$}

Trauma-informed care (TIC) is an evolving, organizational approach to recognizing and responding to the impact of trauma on people (National Association of State Mental Health Program Directors 2013). Using strength-based methods, TIC emphasizes creating physical, psychological, and emotional safety for both clients and staff. Providing trauma-informed care adds another dimension to other strength-based approaches like harm-reduction, motivational interviewing, cultural competency, or positive youth development. It brings brain development, brain function, and the nervous system to the forefront when discussing safety and working with human beings. To set the tone for trauma-informed care to filter through an entire organization, staff members at all levels of an organization should shift from asking "What is wrong with you?" to asking, "What has happened to you?" using a trauma-informed approach toward staff members as well as clients an organization serves (Coccoma and Evans 2014, 4). TIC aims at fostering opportunities for those affected by trauma to rebuild a sense of control and empowerment (Hopper et al 2010). Further, TIC attempts to minimize retraumatization.

Blue Sky Youth Programs, including Inanna House, considered itself a traumainformed organization. Staff members at all levels of the organization theoretically understood the basic mechanics of trauma and how the effects of it might manifest in the youth the organization served. This included seeing the behaviors of youth, such as 
emotional outbursts or difficulty reasoning, as behaviors that did not correspond to the youth's current age because of how trauma can disrupt the development of the brain. For instance, as a fifteen year-old, Simone's request for a staff member to sit with her while she fell asleep reflected that her need for help self-regulating corresponded with the need of a developmentally younger age.

Problems arose, however, when staff members were confronted with each specific instance a youth acted in ways that revealed trauma's impact on their cognitive development or capacity for emotional regulation. In a review of the literature on traumainformed care best practices across disciplines, such as medical care, child welfare, and juvenile justice, some practical tools have been developed and disseminated but they require commitment and a lot of practice by the staff (Adams 2010; Blau et at 2014; Connors-Burrow 2013; Kenny et al 2017; SAMHSA 2014). Further, across settings, translating trauma awareness into changing how various providers implement their care happens slowly and with difficulty due to incorporating the new perspective into complex bureaucratic systems.

\section{$\underline{\text { Methodology and Ethics }}$}

To collect data for this thesis, I used several qualitative research methods. I started working at Inanna House as a relief residential counselor in the fall of 2015, at the same time I started my graduate coursework. As an employee of Inanna House, I built on established relationships when I began my research in the summer of 2017. Observation, participant observation, and semi-formal and formal interviews from a convenience 
sample of participants happened after I received approval from Portland State University's Institutional Review Board.

I interviewed ten youth and five residential counselors who had lived and worked at Inanna House at some point during the 3 months I conducted research. I did not interview administrators because of time constraints and unavailability of administrators due to various reasons. The absence of their voices may appear to create an echo chamber of residential counselor perspectives, but it also allows direct care staff members experience to be underlined. During the window of my research, only three other youth accessed Inanna House services and chose not to participate. The challenge of reaching out to past residents and the low number of residents during my research window created fewer people than I had hoped for this study. In addition, the convenience sample created a sampling bias toward youth and staff members who were more interested, more outgoing, available, or more bored with other program routines. This bias may have caused me to miss the voices of youth who were new to Inanna House and Blue Sky Youth Programs, as well as youth who struggled with more severe mental health issues.

At the time of my research, the demographics of the full time residential counselors at Inanna House consisted of 5 African American staff (4 women, 1 man) all over the age of 35, 5 white staff ( 3 women, 1 man, 1 transman) all under the age of 35 , and 1 Latina staff under the age of 35 . The relief residential counselor pool consisted of a fluctuating 4-7 white women under the age of 35 . The supervisor and director were also white women under the age of 35. Faye, a 17 year-old African American youth said, "It's really good to have just different cultural backgrounds because most of the - let's get real - most of the people that come to Inanna House are black. And it's a higher probability to 
be in that lifestyle if your black." These demographics speak to a variety of themes, many of which I do not take up in this thesis. I would like to note, however, that these demographics flavored the interactions and communication at Inanna House.

The organizational culture also colored experiences at Inanna House. Residential Counselors (RC) were paid an average of $\$ 12$ per hour and spent 40 hours a week attending first hand to the needs and crisis of 1-7 severely traumatized youth. Supervisors acted as a bottleneck for all decisions at Inanna House, which put a lot of pressure on them. They spent most of their work day busy with the hiring process for a constant rotation of positions that needed to be filled. In addition, supervisors' work removed them from the daily flow at the house, causing RCs to dump their frustrations on them. The director oversaw three programs and acted as another bottleneck for decision making for all three programs. Staff members across programs projected all the program's problems on whoever held the director position. To exacerbate the situation further, there existed little transparency within Blue Sky Youth Programs. For instance, residential counselors did not know what the supervisor, case manager, or director really did. Toxic levels of stress and vicarious trauma permeated Blue Sky Youth Programs and Inanna House and hampered the programs' efficiency and effectiveness.

Though all staff were interested in participating in the research project and consented to observation, a number of staff did not follow through with scheduling interviews. Nevertheless, the data I did gather adds missing voices of youth and direct care staff to scholarship on domestic minor sex trafficking. For my analysis I transcribed and coded the interviews using a grounded theory approach (LeCompte and Schensul 
2013). All names, including those of the umbrella organization, the shelter, youth, and the staff members, have been changed and pseudonyms used in their place.

Professionals who may come in contact with vulnerable populations are required by law to be trained as mandatory reporters of suspected abuse or neglect. Sometimes, youth did not want to reveal incriminating information about their exploiters and would only share details about their trafficking history with someone who was not a mandatory reporter. Sexual Assault Resource Center advocates were the only uniquely positioned providers who could offer confidentiality, not required by law to make neglect or abuse reports. For this research study, I chose not to ask youth about the circumstances that led them to seek out and be eligible for Inanna House. I did this because as a staff member I was a mandatory reporter and because even if they kept traffickers anonymous, youth often did not share the details of their trafficking history with residential counselors. If a youth did not share details with me directly, the only information I had access to were the intake notes that included some but not all precipitating circumstances. In many ways, the specific details of exploitation were not important for doing my job. Because I was continuing to work as a residential counselor as I did research, I respected the unspoken privacy about youth's involvement with trafficking that existed between the residential staff and youth.

\section{Emotional Labor}

Starting in grief, here, at the keys of the computer. Though grieving has gone on long before, now grief is the land I live in. Maybe others live here too, still learning how to speak a common tongue. I sit in grief. I am heart broken. What of my pain? What of yours? (fieldnotes) 
I began this project, and paused, and faltered, as grief overtook me. Grief was a word I said like a rosary. It was the rope ladder I climbed to care for myself, and then became my life jacket. Life a lake of sorrow, grief my life vest.

Rather than bracket my grief, I am attending to it ethnographically, acknowledging the ways that personal griefs were augmented by my involvements and relationships at Inanna House and released there as well. Through my work as a relief residential counselor, I became more resilient in my capacity to sit with other people's pain. Through my relationships with the residents, through being present with them through the mundane moments of life, I experienced a relief from the weight of grief that at times felt overbearing. In writing this ethnography, I am constituting the lives of my informants in certain ways, but also, through writing and researching, this ethnography has come to constitute me in new ways as well.

I finished drafting this thesis two years after completing data collection. It is precisely for allowing the messiness, the complexity, and downright tangle, that I needed, and took, the time I did to engage with writing. In fact, in the summer of 2017 I caught the program's death throes, for the county pulled its funding from Blue Sky Youth Programs' CSEC shelter contract in the fall of 2017 and Inanna House was forced to shut its doors. Crisis had been mounting for the program for a number of years, and the county had pressed for higher numbers of youth served, better outcomes with job placement and education goals, as well as more stability in staffing and management. The county finally decided the shelter had become too unstable, making it unsafe. The chaos and confusion that I describe in this thesis reflects these last few months of a failing program. But, I had 
been working at Inanna House since the fall of 2015, and things were not so different then.

I worked as a relief staff for other programs within the Blue Sky Youth Programs organization, but I have not returned to work in any capacity for them since September 2017. This has allowed me to regain my own breath. Apart from the personal losses I have experienced in the past two years, which were many, I have also taken the time to process the grief about the shelter closing. Disengaging with the daily messiness of life in a certain place and within certain organizational systems has given me the ability not only to make some sense of that place during the time I spent and conducted my research there, but also to relate to the complexity and unfinishedness without so much personal charge.

Though I will discuss a lot of complications to care that arose at Inanna House for both direct care staff and youth, meaningful and deep connections were made there. Despite all the difficulty I describe about Inanna House in this thesis, once the shelter closed many youth sought out continued relationships with former staff who had moved to work in other agencies. This crucially shows that even in failing, Inanna House had also succeeded.

More importantly, the delay in writing has given me the time to find some internal quiet in relation to certain aspects of youths' and staff members' stories that touched me. To comprehend mentally, relate emotionally, or fathom on any level, other people's pain is a question well discussed (Scarry 1987; Sontag 2003). "Pain," Elaine Scarry writes, "is enormously difficult to describe in words.... It also actively destroys language, reducing sufferers in the most extreme instances to an inarticulate state of cries and moans" 
(Scarry 1987, 5). Comprehending someone else's precise experience of pain is challenged by pain's inexpressibility. My ability to stay present with people through their suffering requires time for me to process the pain I empathize with.

One way I process my experience and the world around me is through poetry. I include poems I wrote at the beginning of each chapter to express this other way I have come to understand the material of this thesis. Poetry within the thesis also creates a space for the reader to take a moment and move out of the linear logic of the prose. As Joao Biehle and Peter Locke make a call to "attribute to the people we study the kinds of complexities we acknowledge in ourselves, and to bring these complexities into the forms of knowledge we produce and circulate" (Biehle and Locke 2017, 3), I have tried to wedge a space in research for emotional labor and the often non-linear and dynamic ways we actually experience life as it unfolds.

\section{$\underline{\text { Overview }}$}

The thesis contains five chapters: this introduction, three body chapters, and a conclusion. Chapter 2 uses a macro lens to explore historical, political, and economic trends in relation to prostitution and sex trafficking, as well as how these trends intersect with concepts of race, class, gender, sexuality, and age. I focus on violence as a continuum, using structural and symbolic violence to see the effect that structures have on individuals based on social locations. Services for sexually exploited youth act as an ineffective solution when they fail to address the structural and intersectional components that create the conditions for specific instances of exploitation to take place, even as "exploitation" remains a contested category by various sex workers and sex work 
activists. Additionally, in this thesis I argue that harm is done to vulnerable youth when services based on a premise of 'rescue' or 'social control' and mired by large bureaucratic and systemic/structural mayhem cause dysfunction, mismanagement, and shelter closures.

In Chapter 3 I explore the ways humans and institutions move around, and sometimes through, a shared human vulnerability. By considering the functions of trauma and youths' experiences of resilience and relationship, I make a case for care based on interconnection. Some rules and procedures at Inanna House sought to consider trauma's impact on the mind and body of youth, but these rules and procedures often faltered with inconsistency forming traumatropisms instead of trauma-informed care. Using the lens of commensurability oscillating between a disciplinary gaze and a deep relatability, I draw out the evidence for the tangle of care and control in the setting of a shelter for commercially sexually exploited youth.

Chapter 4 considers youth and staff experiences of living and working at Inanna House. I focus on how Inanna House uses techniques of total institutions and disciplinary power along with aiming at trauma-informed care to structure its program, and how all three of these techniques often fell apart. My research revealed that shifting sets of relationships destabilized rules and the consistency rules require. In the cracks of the crumbling foundational structures though, I bring into view instances of what I call 'becoming' (Deleuze 1997). Becoming refers to the ways both youth and staff disrupt roles based on discipline and control, or roles based on being trauma-informed, by being more malleable, more desiring, and more unknown than the structures around them 
account for. I bring into sharper view the ways in which the lives of youth and staff are always unfinished, always in transition.

Finally, in Chapter 5, the conclusion, I discuss the ways I have attempted in this thesis to not foreclose on the vulnerability and uncertainty of lives as they unfold, instead remaining open to lives in a process of becoming something new (Garcia 2010, 35). I return to the role of grief, often missing in the organization of care in institutions like Inanna House. I touch on how the continuum of violence also points to the continuum in which repair and reintegration happen. I try through this thesis to express the complexities and connections, the messiness and tenderness, running through the relationships and institution of a shelter for commercially sexually exploited youth. 


\section{CHAPTER 2: A Continuum of Violence}

\section{Goddess of Mending and War}

\section{Damn.}

The pain again.

At first it was all around me, a seeping fog.

Then it was the crusted carmine wound between my breasts.

Poor, precarious, narrow bridge

where the dragons, the lion-dragons are fighting.

And the pit,

the heart,

or is it the sea, where falling becomes failing,

it is not one fighting one,

it is many, always many, fighting many.

What more does she want

Goddess of white peonies

Goddess of white hair

Goddess of green vest, yellow flowers

Goddess of black eyes, red scowl

Goddess of tigers and stitches

Goddess of blues,

always the blues.

I'm hanging,

wood splintering under fingernails

hair ripping at roots

no fame or fortune

only shadow,

slate,

steel blue,

shale.

\section{Surviving}

Grace, a 48-year-old African American full-time residential counselor, had been working at Inanna House for almost four years. She had also been a client of Blue Sky Youth Programs when she was 16, as well as a resident of a number of area treatment centers, lock down residential programs for girls, youth correctional facilities, and the 
Juvenile Detention Home. She said that none of these interventions helped her change her life. As with many people who as youth were involved with treatment and correction facilities, Grace had a history of trauma. And as with many youth who have been sexually exploited, she also had a history of sexual abuse. "Cuz the things that they say about being in this specific life and style and being in this specific area of work (prostitution)," she told me during our interview, "is that, either fight or flight." She ran away frequently as a youth from a variety of placements because she wasn't ready to process her trauma. She said, “So, mines was flight. I didn’t feel like fightin you, because I knew I wasn't ready, so I didn't waste nobody's time.” Survival mode was how Grace persevered.

Grace continued to be involved with the commercial sex industry, or "The Life," into her adult years. At one point, she was arrested, charged with prostitution, and put on probation. Still fearing retribution from her pimp even though she did not turn him in, Grace chose instead to violate her probation and leave the state after the prostitution charge. Then, Grace lost her 6-month-old son, father, grandfather, and mother within a year of each other. She chose to return to Oregon to turn herself in. Back in jail, she asked, "Can I please talk to somebody?" She told me in our interview, after losing so many people in such a short time, the stress and grief caused her to want to finally get off her chest some of what she had been holding in for so many years. Somehow, she did not have enough room for all the trauma and the new grief both.

When Grace finally spoke with someone, though, the first thing they wanted to do was medicate her. She told me that she said, “I don't want no medication, all I want to do is talk. That's it. But every time I came, it made me feel uncomfortable because I don't 
want to take your medication, just, medication is not the answer for me." Grace felt really let down. In a way, she felt ready for the first time to open up and receive help. The help she sought was someone to listen. She felt she really needed to get it out, to not keep inside, all the pain eating away at her. Speaking about some of what happened in her life would help ease some of her pain, but the social services and punitive systems that had woven through her life since she was 11 years old were not offering this kind of care.

When Grace tried to get her first job outside of prostitution, the hiring manager saw the prostitution charge on her record on the job application and asked her what she would 'do for him' if he hired her for the job. This felt demoralizing. Grace said, "That made me feel like crap! He put me in the same category as I was before. So, it made me feel even lower because I really tried to get myself together and then had to get ran into that." As Grace tried to start anew, she had to navigate the stigma and associated obstacles of her previous life. On the recommendation of a teacher, she applied to work with trafficked youth. She found that working with CSE youth gave her the opportunity to give back, use her experience to help others, and be reminded why she firmly committed to leaving 'The Life' behind.

Grace's story points to several themes I will explore in this chapter. Her experience with the juvenile justice system, her treatment as both a victim and offender throughout her life involved in prostitution, and the challenges of shaking the stigma of her record point to larger trends in approaches of policy, policing, and care. Using the lens of structural and symbolic violence, I discuss how much of current mainstream antitrafficking advocacy in the United States connects with historical movements tied to ideas about childhood, sexuality, race, and gender. 
$\underline{\text { Structural and Symbolic Violence }}$

Viewing domestic minor sex trafficking from a wider political and economic perspective expands our understanding of what youth experience and why. The anthropological concept of structural violence originally formed out of a Marxist conceptual framework that sees capitalism weigh heavier on the working class. Paul Farmer defines it as "violence exerted systematically, that is, indirectly by everyone who belongs to a certain social order" (Farmer 2004, 293). The lens of structural violence helps bring into view the ways domestic minor sex trafficking is framed within systems of care tied to juvenile justice and how macro level factors, like systems of governance, create unequal suffering (Chaudhry 2004). The idea of structural violence can be taken further by understanding "the way everyday life is shaped by the historical processes and contemporary politics of global political economy as well as by local discourse and culture" (Bourgois and Shepher-Hughes 2004, 22). Some anthropologists propose conceptualizing violence as "operating along a continuum from direct physical assault to symbolic violence and routinized everyday violence, including the chronic, historically embedded structural violence whose visibility is obscured by globalized hegemonies" (Scheper-Hughes and Bourgois 2004, 25).

The framework of everyday and structural violence allows us to see that violence does not end when someone in need reaches the doorstep of a shelter, or that violence only touches our informants or clients. The stigma Grace faced from the hiring manager and the insistence on medicating her when she felt emotionally and psychologically distressed points to everyday violence she had to navigate as well as the systemic 
violence she faced. Another example includes my coworkers waiting for their names on section 8 housing lists while youth, who were ready to take the next step out of the shelter, could not afford any housing on their minimum wage paychecks.

Symbolic violence brings into view the embeddedness of violence affecting people through social locations and subjectivities. Pierre Bourdieu (1977) developed the idea of symbolic violence to discuss the relationship between a person's agency and the structures in which they live. In particular, symbolic violence identifies the constraints imposed on people unequally due to their social location. People experience disadvantages due to identity, be that a category imposed from the outside or internalized as conceptions of the self (Brubaker and Cooper 2000). Discrimination such as racism, sexism, and ageism provide some examples of symbolic violence at work.

Further, recognizing symbolic violence brings structural violence into sharper view. Slavoj Zizek clarifies how some violence gets normalized in the everyday by explaining it as the "often catastrophic consequences of the smooth functioning of our economic and political systems” (Zizek 2008, 2). In many ways, symbolic violence, violence done to individuals based on certain aspects of their identity, submerges the systems' political and economic structural violence that "may be invisible, but must be taken into account to make sense of what otherwise seem to be 'irrational' explosions of subjective violence" (Zizek 2008, 5). Understanding lives of youth and staff at Inanna House requires keeping these wider contexts in mind.

\section{Conflating Trafficking with Prostitution}


In the US, the association of trafficking with prostitution goes back to the beginning of the 20th century. Social change, migration, and urbanization created tensions that generated narratives about white women forced into prostitution, not by economic circumstance but by exploitation (Bernstein 2010). In her essay "Human Trafficking: Sketchy Data and Policy Responses", Jo Goodey writes,

The association of slavery with prostitution, and particularly with concerns related to the 'white slave trade' in women, came to a fore at the beginning of the 20th century. Since this time, the specific crime of trafficking has been linked with prostitution of women and, more recently, children, and less so with other areas of 'slave-like' exploitation in the labour market $(2008,422)$.

The movement against the 'white slave trade' brought about the first legislation against commercial prostitution with the White-Slave Traffic Act, or the Mann Act of 1910. The Mann Act "made it a felony to transport knowingly any woman or girl in interstate commerce or foreign commerce for prostitution, debauchery, or any other immoral purpose. It also made it a felony to coerce a woman or a girl into such immoral acts" ("Mann Act" 2015). Kelli McCoy (2010) discusses the ways in which the Mann Act quickly became a way to regulate sexuality. In "Claiming Victims: The Mann Act, Gender and Class in the American West, 1910-1930s," she writes that the Mann Act "involved a constant negotiation over both the legal and cultural meanings of victimization" (McCoy 2010, 9). After two amendments to the law in 1978 and 1986, the broad language of 'immoral acts' was dropped. Gender-neutral language was added in 1994. These amendments to the Mann Act also refocused the act to add emphasis concerning the sexual exploitation of minors ("Mann Act" 2015). Much mainstream contemporary advocacy against sex trafficking utilizes a historically primed tropes driven by melodrama to conflate trafficking with prostitution 
and prostitution with a racialized narrative about the chastity of white women (Vance 2012; Weitzer 2007). Advocacy groups from abolitionist feminists, evangelical

Christians, conservative and liberal government officials, and the media portray the story of trafficking through a sensationalistic decontextualized lens, where trafficking-as-rape and sacrificed virginity persist (Bernstein 2012, 49). As Carol Vance writes in her essay, "Thinking Trafficking, Thinking Sex,"

Virtually unchanged from its nineteenth- century versions, the modern melodrama of trafficking performs various reductions that erode the innovations of international law: trafficking again means prostitution (forced or voluntary); the trafficked person is a woman or female minor; the danger and injury are sexual; and the nature of the crime is an offense against society and morality (for evangelical activists) or against women's equality (for anti-prostitution feminists) $(2011,139)$.

Vance further points out that this trope "replaces the trafficked person's claim to multiple rights with a single remedy, the right to be rescued" (Vance 2012, 139). Once removed from their immediate exploiters, the focus on rescue rather than rights violations may add to the challenges faced by CSE service design and implementation that views youth only as victims.

International and national legal frameworks define trafficking rather narrowly and assume that the trafficked women and minors need to be rescued. The laws and policies view these women and youth as victims who lack agency. If they did have 'agency' and chose to do what they are doing, they would then be viewed as either economic migrants or sex workers, both of which are stigmatized groups. The emphasis on sex trafficking and the downplay of other forms of forced labor and economic exploitation highlights the connections to historical trends that impose moral narratives unequally impacting youth 
according to gender, race, class, and age. Interactions at Inanna House took place within this wider legal, social, and moral context.

\section{Carceral Feminism, Juvenile Justice and the 'Victim-Offender'}

Structural and symbolic violence flow in and out of each other through people's lives. Structural violence often comes into play once a youth is defined as a minor victim of sex trafficking. Detention, foster care, and residential shelters/programs like Inanna House resemble each other in who they house and how they govern their residents. Even though CSE youth are deemed worthy of rescue, often the first point of contact for their 'rescue' is through arrest. Similar to Angela Garcia's (2010) discussion of care in heroin detox clinics where people are court mandated to detox, youth picked up by law enforcement may also be court mandated to CSEC lock down residential programs. In the long run, this initial punitive contact impedes youth from developing trusting relationships with police and other service providers.

Mainstream anti-trafficking stances often lead to results in policy and implementation of services that continue to blame, stigmatize, and criminalize people. On the other hand, a critical understanding of anti-trafficking advocacy invested in the implications of symbolic and structural violence questions the use of a punitive and carceral paradigm to consider a way to justice (Kim 2018). Women's studies and sociology professor Elizabeth Bernstein discusses the ways in which the anti-trafficking movement is "fueled by a shared commitment to carceral paradigms of social, and in particular gender, justice" $(2010,5)$. Bernstein coined the term "carceral feminism" to describe the ways in which anti-trafficking feminists advocate for an approach that "sees 
increased policing, prosecution, and imprisonment as the primary solution to violence against women" (Law 2019). Bernstein argues carceral feminists do not acknowledge the ways police are often associated with, and the harbingers of, violence. Anarchist activist and writer Victoria Law writes, "race, class, gender identity, and immigration status leave certain women more vulnerable to violence and that greater criminalization often places these same women at risk of state violence" (Law 2019).

For CSE youth in the United States, a carceral politics drives the role of police in the task of rescuing youth. Despite many CSE youth not trusting police because of traumatic past experiences with them, many anti-trafficking advocates see arrest as the only way of finding youth safety (Williams 2009). Police relationships with sex trafficked youth exemplify the tension in the role of police to both protect and punish. Through their efforts at maintaining a monopoly on violence, the police both enforce and wield the State's power, connecting the various institutions the State oversees- from prison to the foster care system.

Social services coordinate with law enforcement for arrest (viewed as rescue) and surveillance, putting potentially trafficked youth into more contact with police. In her book Control and Protect (2016), Jennifer Musto explores the ways in which the boundaries between punishment and protection, victim and offender, and state and nonstate authority are blurred. Whether the result of a lack of services or the outcome of historic precedent of detaining youth for their involvement in prostitution, Musto found that social workers, advocates, and police involved with CSE youth viewed arresting them as "the best way to assist them" (Musto 2012,13). As Grace's life story highlighted at the beginning of this chapter, many youth, especially youth of color, will experience 
both victim-centered and offender-focused approaches in relation to the same group of issues in their lives (Crenshaw 1991; Crenshaw 2015). For instance, sometimes when a youth runs away from home they might be picked up by police and brought to a homeless/runaway youth shelter or sent to a lock down group home. Further, social services like foster care, group homes, and homeless shelters are interlinked with punitive and lock down rehabilitation facilities as ways to address commercial sexual exploitation of youth.

Police-youth contact, and associated courts and detention, join together with social worker-youth contact, and associated shelters and foster care. An incident with a youth at Inanna House offers an example of "collaboration and cooperation," what Musto identifies as "novel organizing principles to help reconfigure and augment the criminal and juvenile justice systems to include more rehabilitative social services" (Musto 2013, 28). Keisha, a 16 year-old African American youth, was released on probation to Inanna House after serving 14 months in detention for grand theft auto. When she left Inanna House too many times without pre-approval, her probation officer arrested her at the intake center and brought her back to detention for breaking the terms of her parole. The terms of her parole were to abide by the rules of Inanna House. After 10 days in detention, Keisha was released back into the guardianship of the Department of Human Services via Inanna House. This collaborative approach was also used when police brought youth to the intake center in cuffs to access homeless/runaway or CSEC services. Social services, collaborating with police, shadow many of the governing techniques of the State. As a number of feminist scholars have highlighted, this collaboration with law 
enforcement, a punitive protection model, often disproportionately impacts youth of color vulnerable to overcriminalization (Crenshaw 2015; Richie 2012; Musto 2013).

Often, the way social services and police collaboration look on the ground has complicated consequences for many youth. Growing number of states have passed 'safe harbor laws' attempting to carve out further legal legitimacy and precedence for youth under the age of 18 who are arrested on prostitution charges to be treated as victims rather than offenders (Lloyd 2012). But, as Musto writes, "The switch-up most youth experienced...indicates the precarious dimensions of their legal status and the challenges that come with dealing with carceral agents and interfacing with the justice system" (Musto, 2016, 112). One youth I interviewed spoke about this, saying, "Yeah, it's borderline. It definitely depends. It depends on the age. Any minor should be considered a victim. Any minor." The youth emphasized that law enforcement should view minors as victims, regardless of any other factor involved. But often a youth's race, drug use, or other circumstances precipitating police involvement could impact the approach of police.

In addition, police may at first confront the youth as an offender, arresting them and bringing them to a detention center where they then reveal they aim to protect them. Another youth thought they saw a police car during out interview and exclaimed, "Ooh, I thought that was a cop car! You see how I jumped up?" When many youth do not view themselves as victims, and don't view the police and being arrested in a positive light, police are put in a position where they must use the tool they have- force - to keep the youth in protection. 
A number of studies on girls in the US involved with the juvenile justice system found that Caucasian girls "were significantly more likely to be recommended for a treatment rather than a detention-oriented placement than either African American or Latina girls" (Chesney-Lind and Shelden 2014, 56). This trend has been found to be true for youth picked up on charges of prostitution as well (Musto 2013). Once youth are removed from scenarios of exploitation, they enter a situation in which police and social services work together and treat them as both criminals and victims. After leaving a life of sexual exploitation, they continue to face systemic and everyday racism, low wage labor, and the stigma associated with their past.

\section{Foster Care and the Department of Human Services (DHS)}

Foster care, like education, is one of many ways the State steps in to regulate issues regarding children. Foster care provides a temporary respite by states for children who cannot live with their families. Children in foster care may live with relatives or with unrelated foster parents as well as in placement settings such as group homes, residential care facilities, emergency shelters, and supervised independent living programs. State legislators developed foster care in the New Deal era with the goal of finding children respite while their family got back on its feet during the Depression. The government paid women to care for foster children so that the temporary caretakers would not get too bonded with the children in their care. Foster care evolved into the profession of trained case workers, professional social workers, and licensed foster parents. Professionalization of caretaking by the State meant that both the lives of children and their caretakers became highly regulated, moving away from care organized by kin, neighbor, and 
community. Through federal and state law, the State required licensing for adult care providers and required social workers to track and monitor children's lives.

When the State systematized caring through foster care, the State presided over the criteria for who was worthy of such care. The State bureaucracy created financial and legal hurdles for networks of care in which family, neighbors, or others in the community would help raise children whose families struggled. Catherine E. Rymph, historian of foster care and the welfare state, discusses the ways racial and gender assumptions influenced the shape of foster care and how it became a dismissed form of 'welfare.' She writes,

Until the late 1950s, foster care was among many social services directed primarily to white families. Like other provisions of American welfare, foster care became attached to - and limited by - norms of gender and race that informed concepts of deservingness. The kind of government benefits a child received depended on the kind of family she lived in. Today, poverty and poverty-related neglect play a critical role in determining which children are removed from families and put into foster care (Rymph 2012, 8).

After the New Deal and Depression era, foster care was utilized more and more to take children away from the poor and people of color.

Foster care can be viewed as a bureaucratic state apparatus meant to help. If one zooms out and looks at the historical and political mechanisms that created what foster care is today, though, one can see structures of violence, what Bourgois describes as "historically-engrained large-scale political economic forces [that] wreak havoc on the bodies of the socially vulnerable" (Bourgois 2012, 3). "According to federal data," Stacey Patton writes, "black children are placed into foster care at twice the rate for white children. They are more likely to be placed into foster care than receive in-home services, even when they have the same problems as white children" (Patton 2018, 5). Black 
children stay in foster care longer, receive fewer services, and are more likely to be given psychotropic medications to control their behaviors (Rymph 2012). Once in foster care, a child's life is tracked and monitored. Even as many social workers recognize the structural violence dimensions of foster care, they often must act as gatekeepers to the precarious life awaiting youth as wards of the State.

As a mechanism of protection, legislators developing the modern system of foster care we have today sought more systematic ways to re-conceptualize childhood and formed in the 1930's alongside concerns about white women's purity and agency as well as racist stereotypes and laws vilifying black men (Freedman 2013; Patton 2018). Growing concern for saving children from things like poverty created pressure from social movements to reform statutory rape laws as opposed to focus on the criminalization of seduction (Freedman 2013). Further, the appearance of adolescence as a social category in the early 19th century coincided with an increasing concern for the regulation of the 'moral' behavior of young people (Empey 1982; Platt 1969).

Changing ideas about youth agency and consent color anti-sex trafficking advocacy and drive government interventions. I briefly consider concepts about 'minors,' children, and childhood that frame overarching arguments about domestic minor sex trafficking. This includes the power, right, or agency under law to 'choose' sex work. In statutory rape legislation, overt force or threat is usually not present but rather coercion is presumed because a minor is not legally capable of giving consent to the act of sex in most cases. Statutory rape laws are based on the premise that an individual is legally incapable of consenting to sexual intercourse until that person reaches a certain age. The law mandates that even if he or she willingly engages in sexual intercourse, depending on 
the age of the other person, the sex is not consensual (Cusack, 2015, 10). This framing of the agency and capacity for consent of people under the age of 18 further grounds a view of CSE youth as victims needing rescue.

The title 'Commercial Sexual Exploitation of Children' builds on a conception of a category of 'children' that at once gives legal rights to people under the age of 18 and by doing so creates legal claims about youth's agency, capacity, and ultimately, their freedoms. Estelle Freedman writes, "In the 1930's...just a generation after statutory rape reform promised to extend protection to them, adolescent girls who had consensual or coercive sex were being redefined as prostitutes, the discourse of rape supplanted by one on delinquency" (Freedman, 2013, 161). Increased government involvement in child welfare in the early 20th century through foster care coincided with a move away from rape reform's protection and toward identifying sexually active adolescent girls as 'delinquents' and 'prostitutes.' Since then, in the past few decades, many states, public health departments, and community-organizations have adapted a very different approach of comprehensive sex education and providing contraceptives and reproductive health services to minors in contrast to other initiatives that continue to build on historically situated ideas of youth promiscuity and delinquency.

Protection can be a murky value when shaded by oppressive stereotypes about race, gender, class, and even age. Though foster care theoretically offers safety or respite from abusive or neglectful situations, it often creates a whole other set of challenges for a youth. The history of 'childhood,' 'adolescence,' and correlating forms of protection and care are important guideposts in understanding current debates regarding youth in the tangle of sexual exploitation (Birckhead 2011). 


\section{A CSEC Shelter in Portland: Shelter in the Gray Zone}

Sex trafficking is real and happens across the United States, but faulty statistics play up the melodrama and undermine creating effective ways to address both the local and structural issues of trafficking. Richard Estes and Neil Weiner (2001) conducted a research study in 2001 exploring the prevalence of commercial sexual exploitation in the United States, Canada, and Mexico. For the portion of their study on the United States, Estes and Weiner interviewed 200 homeless and runaway youth in New York City accessing homeless youth shelters. Then, based on the percentage of those 200 youth that identified as exploited, they projected that same percentage onto the number of homeless and runaway youth accessing shelters across the United States, estimating that 300,000 homeless and runaway youth are at risk of being commercially sexually exploited nationwide (Estes and Weiner 2001, 10). Taking such a small sample from one city and making claims about the entire country creates exaggerated assertions about domestic minor sex trafficking. Further, the most comprehensive report to date regarding minor sex trafficking, sponsored by the Justice Department, concluded there is no reliable estimate of the number of minors forced into the sex trade (Kessler 2015). Though the Estes and Weiner claim brought awareness, funding, and programming for a vulnerable part of the population, it also created complications for service efforts on the ground. This is part of the story of efforts focused on trafficked youth in Portland.

Inanna House's story developed out of the larger trends of more focused policy on sex trafficking, more media attention, more funding, and more robust relationships between punitive justice and non-profit social service agencies. In 2009, Portland joined 
for the first time the FBI sting operation called "Innocence Lost." This nationwide action included, with Portland, twenty-nine cities. The FBI identified 7 commercially sexually exploited youth in Portland the night of the sting, second only to the 10 CSE youth found in Seattle on the same night. This caught the attention of the media. In May 2010, Dan Rather reported on a side of Portland at odds with the title 'most liveable' city in the nation. Rather claimed that Portland "ranked second in the country for number of recovered child prostitutes" (Koyama 2012). But the FBI had made no claims about ranking. Further, in another sting operation in 2011, over the course of three nights, only three CSE youth were found altogether in Portland. Predicting trends about the prevalence of sex trafficking of minors in Portland from the small sample size garnered on one-off stings still established a reputation for Portland as a hub for domestic minor sex trafficking and spurred politicians into action.

Portland social service agencies along with local and state government worked together to allocate and create funding for a coordinated cross agency pilot program. In January 2011, Nicole Hannah-Jones wrote in the newspaper The Oregonian in response to the Rather report,

Multnomah County Commissioner Diane McKeel put sex trafficking at the top of her agenda and was a force behind a sex-trafficking bill by Ron Wyden (Senator), expected to pass this year, that would provide up to $\$ 7$ million to local governments that show they have a problem and an additional $\$ 900,000$ for a Portland shelter.

The bill passed. Multnomah county formed a sex trafficking task force and along with Blue Sky Youth Programs created a pilot program for a shelter uniquely focused on the CSEC population and their needs. Multnomah county also created a 'Northwest Conference Against Trafficking' to build awareness and share information about 
domestic minor sex trafficking issues. As an example of the flux of advocacy, browsing Multnomah county's website shows the annual conference only went on for four years, perhaps until the media spotlight moved on. The media attention on Portland, though misinformed, raised an interest in the lives of the city's vulnerable youth, but that interest and support lost momentum and affected how the program functioned and in some ways impacted the life course of the shelter.

As I discussed in the introduction, when Inanna House first opened it was built on current best practices, but low numbers at the shelter (along with administrative and staffing complications that I will discuss further in this thesis) eventually caused the county to pull the funding for the program. The county named low resident numbers, few youth accessing education or employment while in the program, poor supervision practices, and high turnover of staff as the factors that drove their decision. Though many youth involved in survival sex, sex work, or exploitation need safe housing, a residential shelter/program modeled on runaway youth shelters and group homes may not be the best option for this population. Since the shelter shut down, county funds have been reallocated to a new model that focuses on more robust outreach, case management, rental stipends, and safety planning. The new model is reaching and supporting considerably more youth who identify themselves as involved in sexual exchange (personal correspondence with Director of New Day 2019).

Even as many youth and staff felt saddened by the closing of the Inanna House shelter, lasting relationships were formed there. Staff members who continued to work in positions or agencies where youth could stay in touch and stay connected said that they often did so. In subsequent chapters I will explore these bonds of deep relatability and 
examine the tensions in the implementation and structure of shelter services for CSE

youth in Portland, drawing out how youth and staff navigated ambiguous aspects of the shelter/ program. 


\section{CHAPTER 3: The Curve of Trauma}

$\underline{\text { Prism }}$

Colossal heart

too big-

too heavy-

dragged down into earth,

river storming to sea.

Waterlogged-

grief gory-

heart ground to a hollow fury,

heaven bound.

Vanished,

given everything-

everybody-

But the battle-hardened heart

is not yet vanquished,

hoary-

the wild sacred-

speak.

No Way I Was Goin To Fuckin Break

One evening, Gina, a 20 year-old white resident recently arrived at Inanna House, came into the office and requested access to her lock box to retrieve a cigarette. She then invited another youth to come sit with her while she smoked outside on the porch attached to the office. I would have thought the two were old friends, but as I caught snippets of the conversation, I realized they had just met. Gina was talking at a quick pace and in an upbeat tone. She connected with her peer easily and kept them engaged. She filled up the space. 
I overheard Gina telling her peer on the porch, "Yeah I was kidnapped once. I was there for a week. There was no way I was goin to fuckin break for nobody, so I would've ended up dead." "Damn," her peer said, and Gina continued talking about her life with enthusiasm. Her come down off meth and landing safely at Inanna House fueled her.

I was not sure if I heard correctly. The person sitting outside the office, connecting with a new friend, had gone through a dramatic experience I could only begin to fathom. I could only fathom it through my own experiences of trauma, of my own experiences and my own concept of extraordinary events that are filled by ordinary details. And yet, she had survived and continued to be embedded in a social world, a social world that now included me as well.

There is a lot I don't know about Gina, a lot that I do not know about what happened to her. When she would talk about the extraordinary experiences in her life, she would jump around, leave stories unfinished, tell about incredibly intense things and then just move on, change subjects, without any emotional charge, and without skipping a beat.

Over the course of the year I knew Gina, she shared with me more details about her life than any other youth had shared with me; I share her experience, not as a representative example of CSE youth experiences, but as a specific example of the violence and trauma one youth negotiated. The experiences she shared, of people terrorizing her and people helping her, shine light on ways she was broken by human relationships and made anew by them as well.

Gina got permanently kicked out of Inanna House because she broke a bottomline rule about drugs. When I interviewed her a few weeks after she left, she had been 
doing sex work and meth at a motel for the previous week. In our interview, Gina spoke of two kidnapping incidents. The first kidnapping incident happened when Gina was 17. The story came up because Gina had been asked by the receptionist at the motel to help find two teenage girls who were being trafficked. She told me she wanted to help the girls because if people had not helped her, she would not be alive.

At 17, Gina was missing from her foster placement and her foster sister was concerned. Her foster sister didn't think Gina was using drugs at the time and was surprised she had not heard from her. The foster sister's suspicions were further raised when she received a Facebook message inviting her to come party. She passed the information on to the police and according to Gina, the police were then able to find her and this saved Gina's life. Gina explained,

If my foster sister had not figured out that wasn't me messaging her on Facebook, I probably would be dead, because I know I wouldn't have fuckin broke for no motherfucker and he probably would've had to kill me. Period. Because I was so... when I was kidnapped, I was so, every time he fuckin tried to let me out of the closet - I was - motherfucker, I'm tryin to attack, I'm trying to break out, like, I was...going nuts. So, there was no way I was goin to fuckin break for nobody, so, I would've ended up dead. And thankfully- I was there a week. Not, and, if I would've been there anymore it would've been bad, and my foster sister saved my life.

Further, her post traumatic stress prevented her testimony to be used to prosecute the kidnapper. She said,

A sex offender will get less time than a drug dealer any day. The man who fuckin kidnapped, raped me, and two other girls, and was prostituting us, the two girls were scared, so they didn't say anything. And with my PTSD issues and everything, my story was too inconsistent, had too many inconsistencies, so they dropped everything. That man walked free.

Gina spoke of the affect the fragmentation of the experience had on her; things went downhill after the traumatic experience. In this short illustration, one can witness the 
fragmentation that occurred when recalling and trying to talk about the incident. Repeating herself by saying "I was so...," breaking off mid-sentence, "I was so...," saying actions she did but not what she was, "I was..." then never finishing the sentence, "I was...going nuts" she finally claims. This staccato speech gives a glimpse of the terror and the survival mechanisms she used to get through the experience.

I invite you to join me to take a moment to feel the impact of Gina's story. Pause, and take note of what thoughts, sensations, or emotions surface within you. I invite you to connect your experience right now, perhaps of rage, numbness, or grief, to personal experiences of vulnerability and support; and then return to Gina's story. By pausing to focus on your embodied reactions, and my own, I aim to disrupt the ways writing and scholarship can foreclose on forms of recognition with the subjects of ethnography. I am making space for our bodies, your body, my body, and the youths' bodies, so that together we can attend to Angela Garcia's call for ways "the suffering of others and the painful forms of recognition it evokes may be a force for care and not a crippling force" (Garcia 2010, 21). I invite you, the reader, to continue this chapter from a place that unsettles the othering of subject and object, carving a space for a deep relatability.

In this chapter, I develop an understanding of the experience and impact of trauma to inform a consideration of what people, and the systems trying to care for those people, have to grapple with. Often both people and systems remain reactive to the hyperarousal tangle of trauma, what I call 'traumatropism.' I argue that the rigidity of rules set up as hierarchical mechanisms of control and disciplinary power cut people off from each other, harming youth as well as staff members striving to care. In addition, when the staff and administration erratically uphold rules that are in place to create a supportive 
structure around the fragmentation of trauma, this also harms efforts at establishing caring relationships. Yet, in the dynamic hybrid system that was Inanna House, where structure dissolved and formed again and again, supportive relationships happened as staff members followed through with rules that exist to foster trauma informed care and connected with youth amidst crisis and chaos.

I also discuss the tangle of a trauma-informed care and the disciplinary gaze. I focus on the ways in which commensurability-as-gaze connects staff members and youth in a manner that amplifies feelings generated by trauma. The gaze amplifies feeling other, feeling less than, feeling alone, all feelings intertwined with the shame left in the wake of trauma. Alternatively, commensurability-as-deep-relatability, or social commensurability, connects residential counselors and youth as members of the same human community and nurtures feelings of acceptance and belonging, which both support reintegration after trauma.

\section{$\underline{\text { Trauma and Incommensurability }}$}

The challenge of grasping violence, for survivors, caretakers, and scholars, lies in the juxtaposition of a violent event with the experience that, after passing through the event, what happened may not be fully known by the person who has felt their life in danger. Cathy Caruth (1996) writes, "Trauma is not locatable in the simple violent or original event in an individual's past, but rather in the way that its very unassimilated nature - the way it was precisely not known in the first instance - returns to haunt the survivor later on" (Caruth 1996, 4). Trauma research shows that the body and mind have 
a number of ways to attempt to protect the person when overwhelmed by perceived lifethreatening experiences.

For instance, the mechanism of dissociation often automatically mobilizes to protect the self in overwhelming encounters. Dissociation specifically causes an inability to remember or know what happened, by "disrupting the usually integrated functions of consciousness, memory, identity, or perception of the environment" (Fisher 2001, 3). The "normal" dynamic integration of the self is disrupted as a way of organizing information for survival, and happens at a neurobiological level. Dissociation is useful because by being able to compartmentalize information, divide attention into two or more streams of consciousness, and alter one's identity, creating distance from certain aspects of the self, one can protect core parts of the self (Fisher 2001, 1). After a traumatic event, though, the dissonance and distance dissociation created within an individual can make it hard to connect and relate to others. Dissociation can create an experience of incommensurability.

Incommensurability acknowledges the ways in which we are distinct, each of us experiencing our pain in our own separate bodies. The physiological responses to trauma, like disassociation and stress, fragment the many aspects of our embodied selves. Fragmentation amplifies the feeling that our life experience is incommensurate, or unlike, the life experience of others. Violet, an 18 year-old white transfeminine youth, said, "How can I have an emotional connection with them when they have no idea what I've been through?" She felt that other youth who had not experienced the severity of exploitation and trauma she had could not cross the emotional distance of their different experiences. She continued, "I can share, but they can never have an emotional 
connection to it, which distances us apart. Not together." Incommensurability, writes Elizabeth Povinelli, "refers to a state in which two phenomena (or worlds) cannot be compared by a third without producing serious distortion" $(2013,320)$. Violet felt that if someone compared their experience with hers they would have to distort her experience because, she felt, no one else could truly understand it.

In many ways, Violet herself was struggling to understand her own experience and negotiating the effect, mentally and physically, her experiences had on her. The adverse effects of emotional and biological reactions to sudden dramatic traumatic stress, like feelings of fear, helplessness and horror, can continue to abide long after an incident. Siegel and Solomon write, "Trauma impacts the self by impairing the integrative capacities of the mind" (Sigel and Solomon 2003, iv). Trauma affects integration at every level, from neurons, to mental processes, to interpersonal relationships; the whole system is interdependent.

Thus, by focusing on the field of trauma, the connectivity of all the parts come into sharper view. Moving beyond trauma often involves physiological, psychological, and social (interpersonal) aspects. Moreover, as Rebecca Lester states, "The reality, of course, is that trauma happens within the flow of a person's life- he or she did not simply come into being at the moment of the event" (Lester 2013, 755). The meaning of the youths' experiences, specifically the experiences that made them eligible for staying at a shelter for commercial sexual exploitation, were embedded in the flow of their life including a dynamic network of relationships.

Recognizing feelings of incommensurability, feelings of one's own pain, at once acknowledges a profound aloneness and implies an interconnection with the people or 
systems that caused that pain. In addition, engaging with feelings of incommensurability also implies that other people are necessary for reintegration, both within oneself and within the social sphere. Relationships shape the mind, and because development is an ongoing process, relationships continue to influence changes in our brain throughout our life (Siegel 2001, 71). As with traumatic events happening within the flow of ordinary moments, moving through the pain of incommensurability happens within and amidst the ongoing relationships in people's lives.

\section{"Traumatropism"}

The other kidnapping incident Gina shared came up because we were talking about intuition, and how she knew when she felt safe. Gina replied, "I've just had too much shit happen to me over the years. Like I had a trick in Ranier one time. He ended up kidnapping me and he's looking at murder charges right now for some, like, two other girls." She could tell something didn't feel right about the situation because as soon as she got there she said, “Man, I don't like this. Soon as I walked up the driveway, I was like, what do you mean you don't have heat in your house? You have to use a fuckin -it runs on gas? Like what?! And it was just, you saw it was just wrong. Something's wrong." She continued,

Of course I had no phone. At the time, like, my home girl (friend/acquaintance) dropped me off. Cuz she got dope out of it. Like, 'yo, here I'll give you some shit if you fuckin bring her to me dududu,' like kind of deal. Like, that's fucked up. Like this is a fucked up situation. And I was up there for like, five days, four days? Four days. Like. That shit sucked. I'm lucky I got out of that situation.

Gina escaped because the family of another girl who had gone missing was sick of waiting for the timeline of the police and took things into their own hands. The family came pounding on the door and the kidnapper happened to not be home. Gina said, "And 
I was out in the shed! And I started screaming and freakin out. I was freakin the fuck out. I was like, somebody come get me, and they broke me out of the shed!" Violence can seem to break beyond the limits of the rules and norms of the everyday, beyond the limits of life because of the proximity and intimacy violent encounter can have with death.

Gina's sense of the world and herself grew out of and around not only the intensity of her experiences but also the liminal spaces of the experience so rarely inhabited. Caruth calls attention to this conflict as an oscillation between a crisis of death and a crisis of life, "between the story of the unbearable nature of an event and the story of the unbearable nature of its survival" $(1996,10)$. Gina said,

I've had too many bad things happen over the years. Like, the fact that I'm still alive and that I'm STILL willing to do this fuckin shit is crazy. But I don't want to do this forever; that's why I always tell myself, 'This isn't forever, this is just for a little bit,' like, you're just doin this just...to survive."

Often, bearing the experience is exponentially more challenging than getting through it alive. The task of living after violence is filled with the need to reassess reality and construe meaning all over again (Zur 1994, 17).

Reorienting after an extremely disorienting experience, like being kidnapped, is a reactive process. The Webster Dictionary defines 'traumatropism' as "a modification of the orientation of an organ (as a plant root) as a result of wounding." Allen Feldman $(2016,164)$ uses the concept of traumatropism to highlight the ways communities and societies re-organize their projects, identities, and histories in response to this sort of curvature around a wound. Feldman discusses the ways institutions, such as social services, recenter themselves around a fragmented reality created by the experience of violence. The physical experience of dissociation and incommensurability gets magnified on a politically constructed scale. Further, traumatropism claims a space for the ways we 
do not have answers for the malleability of the human being negotiating around the fragmentation of traumatic experiences. The concept of traumatropism creates an instrument to draw out instances people and institutions move around rather than through trauma, disrupting the trend to pathologize, diagnose, or claim expertise about people's traumatic experiences.

An organization recentering around trauma does not mean the same thing as a trauma-informed organization. Rather, organizations like emergency shelters and residential programs often react to trauma like living systems, becoming fragmented and dysregulated (Bloom 2006). LeBel and Kelly write,

The collective impact of trauma also affects organizations. Therefore, it is no surprise that providing trauma-informed care in organizations that are already challenged by the demands of service provision is even more difficult when the collective impact of stress on staff and the organization is not recognized and responded to (LeBel and Kelly 2014, 87).

Because staff members throughout an organization may be traumatized by the constant sense of crisis in their agencies, agencies that are treating trauma survivors have themselves become like the dysfunctional situations their clients have tried to escape (Kusmaul et at 2015).

\section{$\underline{\text { Exit and Re-Access }}$}

The concept of traumatropism helps shed light on how and why things at Inanna House did not function smoothly. It creates a way to talk about the challenges of creating systems that require linear organization around the human system that is navigating in and out of severe disintegration due to trauma. In a number of ways, Inanna House tried to attend to the impact of trauma and post traumatic aspects of the youths' lives. Many of the ways the program tried to be flexible, for instance by allowing youth to return after 
repeatedly running away, were attempts to help regulate youths' nervous system; at its very core, stable shelter supports regulation.

As part of a hybrid approach, Inanna House used a harm reduction model, regarding drugs and cigarettes, as well as youths' continued involvement in 'The Life' when they left the shelter. The harm reduction model is a "public health strategy that was developed initially for adults with substance abuse problems for whom abstinence was not feasible" found to reduce morbidity and mortality rates for substance users (KM 2008). Rather than viewing a return to a pimp as a mistake, or as something to be punished, the administrative designers of the program's re-access policy attempted to emphasize the choices youth had to seek safety and stability.

In this vein, any youth could leave whenever they wanted, and youth did leave. The program used the word 'exit' to refer to anytime a youth left without pre-approval. If they were gone for more than an hour (policy often fluctuated on length of time over the course of two years), the shelter would terminate their stay. Once they were considered 'exited,' youth could re-access the program only 24 hours after the time they left. Their bed would be held for 1-3 nights. 'Exiting" or being 'exited,' meant that if and when the youth wanted to return, they would first have to go to Blue Sky Youth Program's intake center, the public location for accessing Inanna House, where they would have to do a full intake again.

If youth spoke to a residential counselor about wanting to leave, the $\mathrm{RC}$ attempted to talk with youth about why and tried to help them make safety plans including giving them bus tickets and offering phone numbers for various resources. This utilized a harm reduction strategy (bus tickets) and a trauma informed lens (safety planning). Staff 
members often suggested that youth stop at the intake office first before they left the program completely. The option of going to the intake office offered youth the time and space they may be needing to then be ready to return to the house rather than leave to the streets. At the office, youth could check in with case managers or crisis intervention specialists to blow off steam or get the break they needed from other youth at the house. Sometimes this was what youth needed to feel ready to return to Inanna House without completely leaving the container of the program. All of these tools aimed at helping youth regulate their nervous system, helping them titrate feeling overwhelmed and full of anxiety.

Many times, though, youth did leave. If they wanted to re-access, they had to go first to the intake center office and do an intake with a crisis intervention specialist. If a youth had only been gone for a night or two, a staff member could get through the paperwork relatively quickly. But the intake center could be busy, and staff could be held up with other responsibilities for hours at a time and unable to complete a returning youth's intake immediately. The wait involved with re-accessing, between waiting to do the intake with staff and waiting for an available staff person to transport the youth back to the house, was part of the 'natural consequence' of choosing to exit. This process was meant to create some deterrence to leaving and to deter continued involvement in trafficking or sex work while living at the house. If the youth planned on coming back hours later or the next day, the re-access policy meant they could not just come straight back home to the shelter. Rather, they had to go and wait at the office for 1-3 hours to go through the full intake process instead. 
The often sudden desire to leave Inanna House and the many times youth decided to return yielded an exit and re-access cycle over the course of months and years. This cycle illustrated one way youth negotiated the hyperarousal and distress of trauma, and one way Inanna House tried to meet trauma's impact on youths' ability to think ahead or manage time. Sometimes, the way the youth navigated their own trauma and the way staff members responded to youth's trauma differed.

The shelter tried to have trauma-informed rules that sought flexibility (such as the re-access policy) while maintaining program boundaries. But erratic flexibility often caused so much discrepancy that I consider it a traumatropism, modifying around the wounding of youth so much to become almost a disservice. Mary, a former Inanna House resident who became a residential counselor said, "Cuz I felt like a lot of the times people (staff), it was like they were holding a piece of glass in their hand, and they don't want to drop it because if they did it was gonna shatter, but it's like that piece of glass isn't glass it's metal and it's gonna be just fine." Mary saw the youth, and herself, as less fragile and more resilient than staff allowed. Mary was referring to the ways some staff struggled to enforce rules or hold youth accountable to program expectations because they thought the youth too delicate. She said, "I feel like everyone was kind of scared and wanted to tiptoe around the trauma that had happened to these clients." A subtle balance between malleability and maintaining boundaries requires perhaps a different context, structure, or frame not possible in a county funded residential program.

Perhaps the way youth organized around their own trauma differed from the way the organizational culture of Inanna House organized around trauma. Sandra L. Bloom and Brian Farragher write, "Unfortunately, teams under the pressure of acute stress 
respond with overwhelming emotions and cognitive impairments. The entire team may engage in behavior that actually interferes with client care or safety and begins to compound an existing problem" (Bloom and Farragher 2011, 158). Youth living at Inanna House felt their life got caught up in a net of technicalities at every turn. If the goal was to maintain guidelines around supporting regulation and engaging with the impact of trauma, then the need for regulation may very well need to include the organizational culture as well as listening to what the youth requested.

Being able to re-access after running away made it possible for youth who were not ready or wanting to leave their lives and relationships out in the larger world in which they were involved with trafficking to still have a place to come to when they felt they most needed it. This allowed them to develop relationships with staff members and work toward leaving 'The Life' when they were ready. Gina expressed this powerfully. She said,

I always knew I had a fuckin place to rest my head when I was feelin my worst. Like when I was feeling really suicidal, I was able to come back there and have a home. And that was ... I was immensely grateful for that. I still am."

She then went on to name the tension at the core of Inanna House's structure that disrupted feeling supported,

But, I don't know. I just have so much frustration with Inanna House now, it's just hard... It always was a catch 22 , like here we're gonna give you this but- here's the catch! Like- hey! And it was frustrating. Like, why? Why you gotta do that?

In the same breath, Gina captured the blessing and burden of Inanna House. Inanna House's policy essentially said to the youth, come here when you need, but when you accept our shelter, you can be sent back out on the streets if you break our messily managed set of rules. Living at Inanna House could feel like an abusive relationship, 
where the abuser gives something a youth really needed, shelter, but held their power, through spastic rule enforcement, over youths' head. It was not that the requirements in and of themselves were the problem, rather how confusing it was for anyone to figure out what the rules ever really were. Inanna House attempted to create a structure that acknowledged the potential meaning for the youth inherent in the trafficking encounter, yet in the same gesture slipped around youths' trauma and constrained them by the imposition of other structures of meaning, such as disciplinary power and a quasi-total institution or a trauma-informed care so flexible it became undone. (These issues I will discuss further in chapter 4.) The shelter's system often clashed with the internal organization of the youth, out of sync with the mental, emotional, physiological, and physical experiences of trauma and its aftermath the youth so often contended with.

\section{$\underline{\text { Pause }}$}

Along with the re-access policy, 'pause' endeavored to insert trauma-informed care into the rulebook at Inanna House. Pause theoretically existed to help youth reset after breaking a rule or not meeting expectations without having the consequence of being exited. Rather than ignore the behavior or escalate it with severe consequences, youth would be put on pause. This gave them the opportunity to build the skill of self reflection, and develop more self-regulation amidst a situation that may have arisen out of difficulty managing anger or other emotions due to trauma. Mary, who had also been a paid peer mentor before becoming a full time staff, said,

Pause was to prevent people from going back if they've been working so hard to move forward. If somebody had a slip up of staying up past their bedtime, they wouldn't necessarily get all these severe consequences for this one thing that happened, they would just be put on pause. 
Pause offered a mechanism for youth to reflect on what had been going on internally that might have contributed to them breaking a rule and how to prevent this from happening again.

Overwhelmingly in practice, though, the implementation of pause undercut the intended frame meant to support trauma regulation and I argue is another example of traumatropism. Part of the pause policy included the case manager deciding how many days of pause a youth would be on after breaking a rule. Being on pause meant the youth basically had the restrictions of a new arrival — they had no personal outing time, only two 15 minute walks a day, and had to go to case management every morning before noon. After 21 days of a consecutive stay youth moved up stages and earned more freedoms as they met certain goals.

The spirit of pause was often lost, though, in all the minute ways it needed to be enforced throughout the hours of the day. Direct care staff members were often not trained or supported in why pause existed and what its aims were and so they were not invested in putting in the emotional labor of engaging with the youth to utilize the intentions behind the pause policy. By poorly implementing pause, supportive relationships along with an aspect of the strength-based model fell through the cracks.

Going to case management every day created a foundation to the tool of pause, but much of the time the youth refused to go. The question became, then, how were youth supposed to work through the problem that caused them to be on pause if they were not actually going to see a caseworker every morning like they were supposed to? The residential counselor was the one who needed to do the heavy lifting to get youth to get up in the morning and rally them into the van to get a ride over to the office for case 
management between $10 \mathrm{am}$ and noon. If youth refused to go to case management, as they often did, the case manager might intermittently offer to speak to them on the phone as a way of meeting them where they were at and using a harm reduction approach. Rather than escalating events when a youth broke a rule, pause offered de-escalation. Often, though, youth brushed it off with an attitude saying things like, "Oh yeah, whatever, I can go on pause and that's fine and then next week I can do whatever I want to do again and then just go back on pause again." De-escalation and self reflection or accountability formed into a sort of grey zone.

Tom, a 17 year-old white male, expressed the ways in which pause, utilized poorly, ended up doing harm. He reiterated Gina's experience of a catch 22 regarding pause. He said, "This is what you gotta do, this is the expectation, then if you don't do it—you're on pause for a whole week. Then they expect you, like for a whole week, you're not gonna do anything. You're gonna go crazy! It's terrible!" Rather than a creative way to renegotiate a relationship to consequences, pause became another form of punishment that hindered youth and deflected attention from the underlying reasons they may have been pursuing whatever action it was that broke the rules.

Rather than supporting regulation, pause agitated feelings of depression and hopelessness. Tom shared in our interview that he often struggled with suicidal ideation and feelings of hopelessness and related those feelings with how he felt on pause. He said, "I think it's harmful to mental states, like for me, when I get stuck at home for a whole week, I get really depressed, and I don't really do shit, I just sleep." Instead of generating the intended opportunity to explore the complexity of youths' emotional worlds, pause turned into a hoop for youth and staff members to jump through that ended 
up diverting from youths' underlying emotions. Using the lens of traumatropism critically pinpoints instances Inanna House structured care as avoidant, dismissive of the real work of engaging with the difficult and dynamic processes of trauma. Additionally, traumatropism highlights how at times, rules and expectations at Inanna House not only bypassed the painful experiences in youths' past, but in detouring around those experiences, could make feelings of sadness and despair worse.

Importantly, traumatropism also develops nuance in seeing the grey zones as well. It shows the ways in which people and organizations try to continue to grow after wounding. Sometimes being forced to stay home allowed youth a break from feelings of urgency to engage with abusive family or exploiters. Pause attempted to both de-escalate a situation and raise the stakes, for youth to take stock of their actions and how their actions could impact their housing. This did not always work, as I have shown, but supports viewing the pause policy as a curve around the wound - not quite sure if deescalation or raising the stakes will better support the youth. Besides identifying policies as reactive in a more negative light, then, traumatropism also describes how people and systems are unfinished, changing, reacting, responding, and desiring to move out of or beyond a wound.

Ultimately, trauma-informed care faltered because so many different staff positions were disempowered. Residential counselors' had the role of enforcers and not decision makers, which sabotaged efforts at trauma-informed care within the organization. I see solutions requiring large organizational overhauls with how the organizational culture operates. Pause is better than getting kicked out entirely, but if youth refuse to talk to anyone, is that only the youths' fault or also the fault of the 
structure/culture of the people they are supposed to talk to? The culture of the organization involved acute and chronic stress for workers at every level of the system, common throughout human service delivery organizations (Bloom and Farragher 2011, 112).

To find a way through this challenging scenario, I look at the idea of commensurability and how it brings into view two opposing organizing principles of Inanna House, discipline and deep relatability. The lens of commensurability presents both the hierarchical gaze of discipline beside the gaze of relatability and care. The gaze of discipline commensurates people's complex experience by flattening them, by emptying them of their nuance and color. If one moves from the position of power-over into a position of power-with, one enters an encounter where two people can become deeply relatable. The gaze of this other encounter, the encounter of deep relatability, aids in reintegration after trauma. I argue that in the small moments when deep relatability, or social commensurability, happened, something crucial and important occurred at Inanna House that supported and strengthened the youth, and in fact, the staff as well. Even if trauma-informed care functioned imperfectly, by demonstrating that commensurability as deep relatability also transpired at Inanna House, I call forth the small successes that happened there.

\section{Commensurability as Gaze}

From trauma, incommensurability, and traumatropism, I subsequently explore commensurability as a lens to view two different approaches to reintegration that happen at Inanna House. Commensurability describes the dynamic, fluid, complicated world of 
Inanna House for two reasons. First, I will consider commensuration as a kind of disciplinary gaze, a mechanism that makes people knowable through a gaze of sameness. Second, I will discuss social commensurability, commensuration understood as a movement that makes people knowable through the possibility that we are all worthy of relatedness, interdependence, and relationship.

People are made commensurate, or comparable, through a third metric, be that money or a body of rules. For instance, jobs make people's time comparable by how much they make; a body of rules make people's actions comparable by the laws that constrain them. Commensurability can refer to how someone's time pumping gas and someone's time stripping at a club are compared by the numerical value of money. When people are made commensurate in this way, the mechanisms of disciplinary power and surveillance come into play; people often self-impose the collapse of their worth with how much money they have or make. Commensurability at Inanna House highlights how, through the use of money, youth were deemed valuable by exploiters (for instance pimps and johns) for acts that are normally excluded from commercial transaction and from youth in general. Not only that, but because of this experience of commercial sexual exploitation, youth were identified and became eligible to come to Inanna House, a shelter designated only for CSE youth. This can be seen as a second instance where the youth are made commensurate by the rules that they then must abide by once a resident of Inanna House. Once in residence, youth had to negotiate being seen as having comparable experiences to each other by being identified as CSE and having blanket rules applied to them no matter their original circumstance. Experiences of trauma may also be made commensurate by a trauma-informed care lens. This links back to both 
structural and symbolic violence; by making trauma commensurable across all youth experiences, instances of youth agency and circumstance can get ignored.

Racialized experiences of trauma also fall to the background when the individual is made similar to other individuals by the measure of a personal or pathological understanding of trauma. Faye, a 17 year-old African American youth, said,

It's good to have someone who can relate to you in different aspects. It's hard as a black girl whose been involved with services, it's hard to connect with the staff and want to tell them about your background but they're just looking at you with a blank stare because they've never experienced it, it kind of feels shitty, so that doesn't feel like something you want to talk about, because you can't relate [to non-black staff].

Faye had developed close relationships with staff of diverse racial backgrounds, but she also advocated for the unique connection with staff that shared experiences of racialized trauma, perhaps of being of color within the social service system or just being a person of color in the Pacific Northwest, or the United States in general. Faye spoke about nonblack staff she had encountered throughout her time involved with social services as relating to her through the gaze, or as she put it, a 'blank stare,' saying “They sound like they're reading straight from a textbook. I feel like Blue Sky hires people who have real life experiences in the world, and I appreciate that."

Through the services of a CSEC shelter, diverse experiences were made into a comparable register. As an example of a possible range of experiences, a youth could be considered commercially sexually exploited because of having nude pictures taken with a boyfriend that was 5 years older than them, working at a strip club at the age of 15 , selling sex to their mother's boyfriend for them and their mother's rent, working as an escort or prostitute within Oregon, or working for a pimp as a prostitute across multiple state lines. The experience of working at a strip club was drastically different from being 
in a physically violent and controlling relationship with a pimp. These examples show that youth were coming to the shelter situated within many different kinds of experiences and relationships. In their essay "Commensuration as a Social Process," Espeland and Stevens define commensuration as not just making things comparable but measuring disparate things by a common metric $(1998,315)$. Espeland and Stevens write,

The impersonality of economic and bureaucratic rationality is vastly enhanced by commensuration, because it standardizes relations between disparate things and reduces the relevance of context. This impersonality is hostile to ethical systems that depend on personal ties (Espeland and Stevens 1998, 320).

This technique of standardization gets taken for granted while at the same time simplifies and condenses the diversity of human experience.

Further, the youth were made uniform by the creation of a shelter for them (within homeless youth services), and became commensurate by the gaze of staff tracking how they spent every hour of their day, who they called on the phone, and who they spent time with out of the shelter. Youth who had been identified as commercially sexually exploited became registered by joint state and non-profit agencies. On the other hand, the youth tenaciously resisted this imposed uniformity, wedging themselves against being defined as 'victim' or 'villain' (Lutnick 2016). By not conforming to the shelter program, not 'doing what's best for them,' not healing, by running away, doing drugs, sabotaging attempts by others to build relationships, returning to 'The Life,' the youth were not only very hard to help, they were also marking the ways in which the rationality of the shelter could not encompass them. The youth's behaviors claimed they could not be judged by the same standards as each other or other runaway, homeless, abused, traumatized youth. Their return to the street, to other relationships, structures, and systems of being disturbed the encompassing rationality of the shelter. These behaviors of resistance to 
'rehabilitation' are often viewed precisely as legitimizing youth's CSEC placement, services designed (or rather designated) for youth who have experienced trafficking, sexual exploitation, manipulation, coercion, trauma and Post-Traumatic Stress Disorder (PTSD), severe shame, dissociation, guilt, trauma bonds, and the like. I argue, though, that youths' behaviors of resistance to the shelter do not only happen because they are not yet 'healed,' but because those other worlds, of the street, sex work, family, and peers also bear meaning and sense. The ways youth push back against the rules, and against becoming known and knowable to the people and services offering help, comes from the tension between commensurability as deep relatability and commensurability as gaze.

For youth who lived at Inanna House as long-term residents, the wait at the intake office to re-access could be frustrating when they just wanted to go home. The policy made Tom, whose history did not involve the specific formulation of trafficking that the re-access policy was predominantly meant for, commensurate with youth in very different circumstances than him. When Tom did not want to wait to make arrangements to go grab food or buy cigarettes through the official protocol of approval, he would sometimes try to make it back within the window of allotted time before being exited, so he could skip the re-accessing process. Sometimes, though, he still got there too late. $\mathrm{He}$ said,

Sometimes it feels impersonal and stuff: "We're just doing this because it's our job," "You just have to do this because it's program expectations." It's shit staff has to do because of how stupid the job is, like the rules, the semantics that are argued. Like, "Oh no, you were ten minutes late past the time you were supposed to be back, so you have to go to the office to walk back." And I'm like, "Are you kidding me? I literally just got home!"

Tom wanted the system to make sense to him; if he was attempting to get home but arrived 10 minutes late, he sought a logic that nurtured regulation, which involved being 
able to enter and relax in the safety of his home. Tom did not ask for no rules, or no boundaries, he asked for consistency with a set of rules whose logic helped him make sense of his trauma rather than exacerbate it. Further, he sought staff members to resolve conflicts through direct communication with him, rather than the occasions like this example in which staff members interactions were mediated through the authority of the rule book.

\section{Commensurability as Deep Relatability}

In the often uncertain and changing space of Inanna House, non-hierarchical relationships happened between the daily staff and youth. These revealed that, despite the inconsistent flexibility and rigidity and the gaze of commensurability, an ethics of deep relatability could also surface beside a unidirectional power structure. Disciplinary power and the gaze flesh out certain mechanics of Inanna House which I will develop further in chapter 4; but subtly interrupting these techniques are moments of deep relatability, or social commensurability. A subtle shift in focus, from rules creating structure to relationships creating structure, brings into view the way a shared space has, as Angela Garcia writes, "the potential to prepare the subject to live again—not without pain but with pain that invites us to visualize another life, one fully implicated with others" (2015, 133). Commensurability and incommensurability between subjects structure the interpersonal and therapeutic domain and lie beyond, beneath, and/or beside the connecting points of disciplinary power and its institutions (Garcia 2010, 51). Garcia writes about an 'ethics of commensuration' as a way to make sense of the closeness and care that passed between herself and a patient in the painful throws of heroin withdrawal 
during a blackout at the heroin clinic where she worked and conducted her research. Her construction of an ethics of commensuration placed her vulnerability, to darkness, to loneliness, to grief, alongside her interlocutor's vulnerability, to darkness, to loneliness, to grief, alongside their pain of their body in withdrawal. The ethical enters commensuration when commensuration presents the positive possibility of comparison. An ethics of commensuration means two people can relate across deep wounding and significant fragmentation.

At Inanna House, hand in hand with the workings of becoming which I will discuss in chapter 4, the staff and youth emerge as subjects to each other through deep relatability and cross-cut the rules, expectations, and procedures within which they are bound. Sociability in the face of severe atomization is a testament to people's ability, and desire, to heal from torture and terror through human bonds (Arendt, 1970). The experiences youth had with their exploiters both destroyed, and made possible, a novel intimacy. Dhana Hughes writes,

Violence carries meaning to those who inflict it as well as to those who are subjected to it. These meanings are overwhelmingly rooted in intimate relationships and are of an ethical nature... Where violence renders a discontinuity or fragmentation of the self, remembering one's troublesome experiences in morally meaningful terms allows for a sense of continuity (Hughes 2013, 170).

Faye spoke about the ways in which Inanna House was a place she and other youth learned "how to be a citizen in the community, without going through the hardships of that lifestyle (the lifestyle of prostitution)." Faye was advocating for participating in the community without the community mediated by being in 'The Life.' Faye, who had been in 44 different foster placements and in and out of prostitution from the age of 13 through 
16 , saw the ways in which it was imperative to create new terms for meaningful relationships. She said,

Everybody deals with trauma in a different way. People who are antisocial and don't want to socialize, who don't want to get out and socialize...I think it's a good idea (to socialize). You do need to know how to live in the world, and realize, some things may have happened, but it's not the end of the world.

Reconstructing meaning comes through reconstructing relationship, a task for the whole community, the whole society, in the wake of violence. Further, I argue that a social commensurability marks the ways in which each person fits in to the meaning of those around them. Each staff member also contributed to the process of meaning making. By relating to the youth through our own suffering, we all were a part of the active mediation of past violence.

In this chapter, I have drawn attention to the intersection of traumatized bodies and an institution of care aimed at sheltering those bodies. I have used the concept of traumatropism to discuss the incongruence that can happen when the fragmented organization of a traumatized system (the individual) must adhere to the linear logic of an organization caught in bureaucratic constraints or the chaotic logic of a traumatized organization (Inanna House). Further, I used the framework of commensurability as a way to describe some of the youth and staff experiences of this incongruence. Incommensurability described the feelings of dissociation from self, and distance from others, someone might feel after a traumatic event. Incommensurability also described one hurdle a traumatized person must navigate on the path toward reintegration with the self and with other people. Then, I described how commensurability highlights two ways reintegration could happen, a commensurability of othering and a social commensurability of interconnection. Reintegration at Inanna House happened both 
through a disciplinary, often economic, gaze which made individual's personal experiences the same, and conversely through a social web that acknowledged the personal and shared dimensions of human vulnerability. 


\section{CHAPTER 4: Discipline and Becoming}

$\underline{\text { Pitter-patter }}$

It's been all the pain

that I do not feel

together with the soft dawn

on a night of lights, eyes open.

I'm not running-

feet pit pat pit pat ting.

The mixture of a fragile body

meant to do everything,

and a thread loose-

all the loss of warmth.

And then,

the pitter patter pitter patter

for the cigarette every hour,

all night long

the endless conversation between

all that is over the threshold.

Please ask me-

ask me as long as you do not use your eyes-

ask me-

for my voice is rusty,

my voice is sore.

\section{Gina and the Piano}

The first time I met Gina, she had accessed shelter at Inanna House after an attempted suicide and was coming down off meth. Once Gina detoxed, she filled her time attending NA meetings, seeing her therapist at LifeWorks NW, seeing other service providers, and looking for a job. Generally, she could not fall asleep until well after midnight, and preferred to sleep late into the morning if her appointment schedule 
allowed. She did not like to be woken up by the sound of another resident playing the stand-up piano in the downstairs hallway at 8,9 , or 10 a.m. Other youth also complained about the piano playing and how it disturbed their morning sleep.

Officially, 'quiet time hours' were 11 p.m. to 7 a.m. Technically, playing the piano any time after 7 a.m. did not break any rules. The director and the supervisor did not want to change the general rule, and so refused to intervene about the piano. Gina decided to take things into her own hands. One day, when everyone else was occupied in the house, Gina glued the entire bottom side of the piano cover shut. Gina creatively made her point and brought her desires concretely into the world. In so doing, she challenged rules about quiet time that characterize a quasi-total institution.

Gina made more than one statement by gluing the piano shut. Five outdoor and four indoor cameras were mounted at Inanna House. The indoor cameras emphasized the presence of surveillance and the staff's watchful gaze, what Foucault (1976) calls disciplinary power. A camera, set up downstairs to point down the hallway of bedroom doors, caught part of the piano in its view.

During one interview, I asked Gina what she thought about the cameras at Inanna House. She said, "I hate those fuckin cameras, man. I always do something to break them, because it's annoying. Honestly, it's kind of fun to try to figure out ways to get away with shit on camera." I asked, "On camera?" "Mmhm," She said, "I made it into a game after a while. A lot of times I really didn't care." "Did you do that other places too?” I wondered. "Just Inanna House,” Gina said, “Cuz I was bored. No one watches those cameras, really." 
Sometime after the piano gluing incident, Gina and I were walking downstairs together and she playfully elbowed me in the side as we passed by the middle section of the piano. I looked at her, and she pointed to the camera and said with a laugh, "The camera doesn't cover this spot." Gina outed herself, admitting implicitly to me she glued the piano shut and got away with it. We both chuckled.

The story of Gina and the piano points to the themes of disciplinary power and playfulness in the context of a totalizing organizational living structure that I will focus on in this chapter. Irving Goffman's (1961) formulation of total institutions describes places where every aspect of people's lives are regulated and kept track of, upheld by the staff hierarchy and staff members' watchful gaze and constant supervision. I will emphasize in this chapter the ways in which Inanna House was a quasi-total institution, but the chaos of real life meant that the institution did not function in the totalizing, surveilling, disciplining fashion that theorists assume such institutions will work. High staff turnover, understaffing, lack of training, and changing rules contributed to the chaos. Negotiating trauma also contributed to it. Moreover, the hybrid design of Inanna House, using harm reduction and trauma informed care alongside discipline and control, complicated the organizational structure.

A contested and sloppy use of disciplinary power by direct care staff members created one of the ways the quasi-total institution fell apart. This happened when individual staff members did not follow through enforcing rules and by youth who resisted and worked around the discipline that was enforced. Often the staff lacked a clear understanding of the rules, along with a clear protocol regarding how to enforce them within all of the various dynamic circumstances that arose at Inanna House. Staff 
members did not use the mechanisms of surveillance set up at the house, either for disciplining gaze or for bolstering their disciplinary efficacy. When staff members did not use the technologies at their disposal for surveillance, like cameras, youth did not take staff seriously as enforcers of disciplinary power more generally. Youth strategically resisted the ways in which surveillance techniques, like the communication log, denied their perspective regarding circumstances happening in their life. Further, youth disrupted the hierarchy of disciplinary power and surveillance through a bidirectional gaze in which they watched the staff and asserted their own sort of disciplinary power on them. Using a bidirectional gaze, youth acknowledged their embeddedness in the relationships that structured life at Inanna House and attempted to shape those relationships and structures.

Thrown into this mix, the appeal for trauma-informed care floundered. When the framework of rules malfunctioned and disintegrated, staff and youth were forced again and again into an uncertain, slippery space. In this tangled setting, I use the analytic framework of "becoming" to identify instances of trauma-informed care in action (Biehl and Locke 2017). Becoming accounts for how people shape relationships and structure through the power of desire, flexibility, and uncertainty. In moments staff did not know what to do, or moments youth saw confusion, I observed people harnessing their own malleability for desired outcomes. Becoming complicated how total disciplinary power theoretically functioned, filling in a more trauma-informed lens when disciplinary power eroded. The staffs' and youths' lives unfurled into unknown possibilities beyond parts of the institution aimed at discipline and control.

Further, becoming highlights the way that people can be playful in how they pursue their desires. The staff and youth at an emergency crisis shelter accept a certain 
degree of chaos in the day to day (dys)function of the place. Trying to modify the behavior of resistant teens while being met with teen's generative creativity and playfulness could amplify the feeling of chaos for the staff while also forming a spotlight on youths' strategic brilliance and resilience. As Joao Biehle and Peter Locke (2017) write, "Our interlocutors in the field are more complex, strategic, and inventive than hegemonic forces and philosophical theories of the subject are able to capture" (J. G. Biehl and Locke 2017, 42).

When staff or youth lost a firm reference for the rationale and coherence of what it was that was happening at Inanna House, becoming surfaced as its own structure, with its own rationale, in which to relate. Staff and youth engaged creatively with each other's desires, while also negotiating the pressures of their social positions within the house. I argue that care, and specifically trauma-informed care, happened because staff and youth had this other structure of becoming — open ended, inventive, and capable of making novel connections. Amidst the complications, Inanna House also created a space for youth to develop meaningful relationships with caring professionals. As Keisha said, "I make my own choices but still have people helping me."

\section{$\underline{\text { Total Institutions }}$}

In a total institution, the staff ideally observes and regulates for compliance every aspect of a resident's life, including time of wake up, time of exercise, and who a resident can engage with. At Inanna House, staff members supervised youth at all times, except in their bedrooms, and the program restricted youth's timetable, movement, and contact with the outside world. Irving Goffman (1961), considered one of the most influential 
sociologists of the twentieth century, founded the branch of sociology/social science concerned with everyday life and social organization. Goffman identified institutions like orphanages, mental hospitals, prisons, barracks, and abbeys that he found shared many characteristics that encompass the 'totality' of resident's social lives. Goffman writes,

All phases of the day's activities are tightly scheduled with one activity leading at a pre-arranged time into the next, the whole sequence of events being imposed from above by a system of explicit, formal rulings and a body of officials. Finally, the various enforced activities are brought together into a single rational plan purportedly designed to fulfill the official aims of the institution (Goffman 1961, 17).

Goffman contrasts his distinction of a total institution with what he saw as the ways in which Western life typically have separate spheres or boundaries between work, play, and sleep.

A quasi-total institution is a place where some contact with the outside world happens but that remains restrictive and controlling of its residents' actions within the confines of its walls (Armaline 2005; Rakowski 2016). At Inanna House, like other similar settings such as homeless youth shelters and group homes, residents leave to go to school, work, and approved personal outings. Although youth had some freedom, Inanna House policy restricted phone use and banned access to social media, fearing the use of those platforms for non-approved activities. As a conceptual tool, total and quasi total institutions explain the bureaucratic organization of Inanna House and frame the rationale for many of the house's structures and goals.

Further, the premise of total and quasi-total institutions can lend themselves to the use of colorblindness and racialized gender constructions. Like the way commensurability of money and the disciplinary gaze disregard structural and symbolic violence, the design of total and quasi-total institutions treat individuals without regard to 
race, culture, or ethnicity thus ignoring and denying the impacts race, culture, or ethnicity have on individual resident's lives. Colorblindness in a shelter for CSE youth then ignores the effects of tropes like naïve white virgins and oversexualized black "jezebels" on the youths' experiences and conception of themselves. Within a colorblind context that ignores the experiences of racialized constructions of gender and sexuality, the vision of transformation (leaving 'The Life,' recovery, or healing) often can reinstate racialized gender constructions (Lawhorn 2018).

In addition, total institutions describe social arrangements that can obscure culpability, as the staff who must enact a grand plan fade from view. By just following the rules, staff members would become faceless cogs in a machinery of control, but humans are not merely components of a machine. In the ways in which total and quasitotal institutions disregard staff as actors, the hierarchy of these institutions reformulate aspects of structural and symbolic violence. In the hybrid setting of Inanna House, direct care staff members pick and choose what rules to enforce, how to enforce them, and for which youth during the many moments of their work day in which youth give them an opportunity to engage with the structure and design of the shelter/program.

\section{$\underline{\text { Staffing }}$}

The staff made and enforced rules for residents at Inanna House. Administrative officials, such as the executive director, director, supervisor, and case manager, had the power to create and redesign rules. Residential counselors (RC) were tasked with enforcing those rules in the daily interactions with youth. Administrators had the final word on acceptable or unacceptable behavior within the program, but the residential 
counselors upheld the rules in the many small interactions with youth throughout the 24hour day.

Frequently, at least one if not two RC positions remained unfilled at Inanna House. Therefore, a pool of relief residential counselors was crucial in meeting the staffing needs for the ongoing functioning of the program. In addition, Blue Sky Youth Programs found it hard to keep full-time RC positions filled long term because of low pay coupled with the physical and emotional labor of working with trafficked youth. Over the course of the two years I worked there, three separate groups of full-time staff cycled through Inanna House. In all three groups, residential counselors quit en masse due to frustrations with how supervisors and directors managed the house and failed to support them.

This pattern of burn-out, residential counselor conflict with administrators, and poor oversight by the executive director left the program often run by the relief staff who picked up shifts to cover for all the unfilled positions. Sometimes, relief staff members essentially worked a full-time or over time position, without the same requirements or supervision full-time staff members theoretically had. At other times, the relief pool fluctuated with an ever-changing rotation of staff and created a lot of instability in the day-to-day consistency of life at Inanna House. When asked how Inanna House could better support her, Keisha replied, "Just if everything was more consistent." The rotating relief RC pool, though, essentially kept the shelter running.

The high staff turnover undermined the effectiveness of the institutions' many rules. Youth found the situation destabilizing, particularly because the lack of continuity created uncertainty. Different staff members each having their own style of enforcing the 
rules exacerbated this uncertainty. Faye said, "Staff would be close with a client, or had a good relationship with somebody, they would let them get away with more things;

whereas someone who they weren't as close with, it was like they were not held up to the same bar that the other person should've been held up to." Youth who lived at Inanna House long term knew the staff's schedules and would anticipate the overall feeling of an upcoming shift or what activities may be possible depending on who would be working. When youth could not rely on staffing routines, they experienced anxiety and stress.

Besides staff turnover and staff changing how they applied rules and to whom, staff members found they struggled to keep all the rules straight. Rules existed, but they changed often. For instance, Lisa, a 27 year-old Hispanic full-time residential counselor, said, "The wishy-washyness - that's what makes it hard. It's because we hear one message, the youth get another message, and then we're both trying to understand like, Why are you doing this? And then they're trying to understand, Why is the staff doing this? And then we're just butting heads." Often, neither direct care staff nor residents understood the reasoning behind many of the rules. Even when administrators like supervisors and case managers had a sense of the logic for parameters and expectations, they were regularly juggling many other tasks and lacked the time to translate the scope of the program down to direct care staff. Frequently, youth strategically maneuvered to get around rules in the confusion.

The people making up total institutions often must adapt to shades of grey. Though on paper certain rules were cut in stone, in practice, staff members had to assess how life in all its complex guises correlated with those rules. As Lisa said, "Everything is 
different every day. Every scenario is kind of different." For example, youth had to call if they were going to be late coming back to the house, say, from work. Lisa explains,

If youth are calling and checking in with us - then yeah, Jackie can come back late. Whereas if they're not calling us and they're not checking in at all- they're probably - that's where we're like, they're probably going to have to exit because they're not contacting us... But, someone could say, 'Yeah, I'm on my way,' but then, it's another hour and a half- so they checked in with us, but then, they're not really coming back (within the window of time theoretically permitted).

Both permanent staff and relief RCs struggled with the ambiguities that arose in the daily life at Inanna House within the framework of a quasi-total institutions rules.

No one seemed to know if Inanna House was an 'emergency shelter' or a 'residential program.' When Inanna House looked like a shelter, more restricted rules with little personal time constrained youth. When Inanna House looked like a program, if a youth engaged with 'programming,' they were rewarded with more freedom and less interference in their lives. Faye pointed out, "It feels like partially a CSEC program, you have to be a CSEC to be in there, but it's also a transitional housing program. But it's like, you've got to pick one or the other because it's not the same thing."

Attitudes of both direct care staff and residents oscillated between less engagement: "Well, it's really only a shelter," and more engagement: "This is a program, it's not somewhere to just sit around all day and do nothing." Gina explained the ambiguity another way: "I mean, because if I look at it from being actually incarcerated, to being in a lockdown facility, to being at a shelter, and a foster home - Inanna House is a mixture of a little bit of everything." This confusion between program and shelter created confusion for the staff so that they routinely questioned their role and the forms of support they were able to offer. 
Sometimes an inconsistent total institution felt abusive. Jackie, an 18 year-old Hispanic and Native youth, said, "I'm very much on eggshells and it's kind of like living with a family member that's really grouchy and can kick you out at any moment in time. Like, that's not what I'm down for... It's like, I go there fucked up, and then I get kicked out.” This feeling of being on eggshells made Jackie insecure when accessing Inanna House's services.

At other times, the youth harnessed the instability at Inanna House to use the dysfunctions of the program to better meet their needs, as in the example below about Gina. One night, inconsistent administrative communication and decision making happened when the residential counselor on shift, Jake, received a call from Gina, at the time not officially in the program. Gina stated she felt unsafe and requested to be picked up and brought to the intake center to access services. Jake, a 24 year-old white full-time residential counselor, had received a similar call before from her. When feeling unsafe and not a resident of Inanna House, she had called for a ride to the office to do an intake back into the program. On that occasion, Jake had been given permission by the supervisor of Inanna House to pick her up. On this night, Jake followed protocol and called the supervisor on call to receive permission. The supervisor on call asked him if he had transported youth in a similar situation before and he said yes, he had previously been given permission by the supervisor of Inanna House. The supervisor on call said then that he could pick Gina up in this instance as well.

Things got sticky when the next day the director and Inanna House supervisor found out what had happened and sent an email to all the staff that Jake described as a “passive aggressive email that was like 'Yeah, we can't pick up youth when they've 
exited." Jake individually got in trouble for doing the transport, even though he had had permission from the supervisor on call. Inconsistency confused the staff and undermined their ability to know how to go about making decisions. Jake felt that he would have picked up Gina even if permission had been denied from the chain of command, because, he said, "I'm going to go pick her up no matter what anyone says, because she is in a bad place." Lisa, on the other hand, felt, "I would like to say that I would do the same, but I feel like my fear of getting in trouble could get in the way of actually doing what's right." What is right, though? Jake thought his care lead him to pick Gina up. Lisa thought her fear would have lead her to make a different decision. The institution officially considered rides to youth not residents in the program a boundary of their scope of services. And yet, a relationship with a particular youth may have driven the supervisor to give permission in one instance for this scope of services to be crossed. And then, when Gina called again asking for a ride, another opportunity to create, maintain, or reconfigure the boundaries of the program presented itself, and the messiness ensues.

Faye, and other youth, asked for less tightened focus on controlling and modifying their behavior and more consistency and transparency. She gave this example,

The whole time I was there they were giving me a week out, a month out, 'cuz I kept exiting. Where other people were doing the same thing, but that wasn't happening to them (being exited). It's not cool. And so, on the one hand they say "Oh well, everything needs to be fair," but on the other hand, when it's rules with people "Oh it's individualized and everybody's different, so worry about yourself," and that's not ok. Either pick one or the other, you know?"

When I asked Grace about how the inconsistency at Inanna House compared to her experience out in 'The Life,' she highlighted the difference, "You mean as far as being out there (involved in 'The Life')? Because there's a routine! There's a routine; every day you do the same thing, and so, when the routine is out of place it feels like there's not no 
structure." Youth, who were already in crisis, came to Inanna House and met more challenges, like “you guys don't even got it together," like the ground was always shifting there. Inanna House attempted to regulate most aspects of the resident's lives, and yet regulated them inconsistently, creating hurdles for youth to come to trust, rely on, and engage with the aspects of the institution that were trying to support positive change in the youths' lives - identified by the program as changes toward being 'self sufficient' and 'productive' adults. But mixed messages from supervisors and directors ended up turning into mixed messages for youth.

\section{Disciplinary Power}

Total institutions (Goffman 1961) depend on surveillance and disciplinary power (Foucault 1979). To regulate the behavior of someone in a total institution, those who run the program need to know what the resident is doing at all times, and the resident needs to be trained to behave correctly. This modification of behavior happens through knowing that they are the subject of "the gaze."

Disciplinary power works without the need of force, for it is "constant, unnoticed, and internalized" (Marshall 2012,7). Michel Foucault's work focuses on the type of power that penetrates into people's lives in such a way that the effect of this power becomes routine and ignored. Using the example of Jeremy Bentham's panopticon, Foucault explains that disciplinary power begins with the gaze of the guards in a tower at the center of a prison. The tower has one-way viewing; guards inside can see out but the inmates outside cannot see in. This set up causes inmates to assume that someone is watching them at all times. In fact, the guards may not be watching all the time but the 
inmates internalize the gaze and, not knowing if they will be caught, are driven to conform to the rules. Foucault writes,

There is no need for arms, physical violence, material constraints. Just a gaze. An inspecting gaze which each individual under its weight will end by interiorising to the point that he is his own overseer, each individual thus exercising this surveillance over and against himself (Foucault 1977, 156).

The penetrating power of the gaze has as its end the making of docile bodies. Inmates, residents, or patients follow rules because the institutions use similar techniques of discipline and these techniques tie together Goffman's total institutions. Through the use of disciplinary power schools, hospitals, factories, barracks, and prisons all resemble each other (Foucault 1977; Goffman 1961).

Life at Inanna House corresponded with the totalizing organizational project by the use of a hierarchical structure of authority, the use of cameras for surveillance, the use of private staff communication logs to record resident activities, and the use of restrictions to regulate youth's contact with the outside world. Each of these interventions was intended to control and shape the behaviors of the youth. More commonly, though, no matter how closely regulated the gaze of the institution, staff must 'read' or 'interpret' any behavioral episode and decide if it is an example of this or that (Kivett and Warren 2002, 5). Staff interpretation of the gaze, and of the rules, often warped the discipline structure.

Disciplinary power affected how both youth and residential counselors thought about their behavior but did not result in uniform outcomes, just in overall stress. Staff members had to decide in every instance if enforcing a rule was worth it for themselves, for that youth, and for other youth in the house. For instance, to complete a meal chore, youth had to submit a grocery list by 10 p.m. Saturday. In some cases, staff accepted late 
lists Sunday morning because they wanted to support youth accomplishing their chores and therefore gaining productive time hours. Part of this decision-making process involved weighing the pros and cons of a situation that felt, as Lisa said, "like I'm going to get my hand slapped for anything — like you're wrong if you do, you're wrong if you don't... It's just like walking on eggshells, with management, with the youth...." Disciplinary power filtering through direct care staff both highlighted how messy and disjointed discipline and surveillance were while at the same time bringing to view processes in which human relationships involved structure and play.

Disciplinary power also included keeping track of the residents' day. RCs recorded in the communication log, or comm log, what each youth had done each day, evening, and night, along with any issues or conflicts that may have transpired. RCs filled the comm log out by the end of every shift, writing (theoretically) in a matter of fact tone without opinions or judgements. Staff and administrators viewed the comm log as a place to communicate to each other about youths' day, fostering consistency and providing a place for notes about anything that needed to be followed up during the next shift. This included details like upcoming appointments or conflict between youth in the house.

While the staff viewed the comm log as simply a log for communication, youth viewed the comm log with disdain and felt it was a place staff recorded their biased descriptions of the youths' lives. The youth experienced it as an aspect of a quasi-total institution keeping tabs on them through the watchful gaze of staff who record their every move. The comm log undermined therapeutic relationship by its 'gaze,' reinforcing to the youth that they were the object, the other. Faye said, "And it just really feels weird when someone is watching you, interacting with you, and then at the end of the day they're like 
typing that all up, like, that's fucking weird." Faye's comment sheds light on how, in relationships not within the confines of a quasi-total institution, having someone watching and recording you and your life is not socially acceptable, and in fact could be viewed as creepy, sending up a red flag. The comm log did not elicit a feeling of community, where part of community care may include looking out for one another and communicating concerns about members of the community.

Utilizing the 'gaze' of disciplinary power, the staff kept the comm log private and off limits to youth. Youth were not allowed to read it and discouraged from asking about what was written there. Not being able to read exactly what staff members wrote, yet knowing they watched and recorded the events and interactions of the day, distressed the youth. Youth expressed that they felt uncomfortable having people write things about them that they could not read. As Faye said, "What if you said some things that were a little unprofessional? Because of course, bottom line is, you know your boss and all these people read it, nobody's gonna put in there stuff that they did negative- right? Unless you're a great person, like the best person ever." Not only do the youth not have access to read or add to the log, some youth felt the comm log put pressure on staff members to seem like they were always doing the right thing and following (that is enforcing consistently) all the rules. In a sense, youth saw the comm log as a mechanism of a disciplinary gaze by administrators watching direct care staff.

Further, the comm log enforced disciplinary power through its function as being a record of what was 'real' - what really happened during a shift, communicated to oncoming staff, case managers, therapists, supervisors, and directors who all had access to it. For instance, Faye said, when "you piss a staff off, rub a staff the wrong way, staff 
can falsify or exaggerate things in the comm log and paint it for me to seem like I'm just reacting so bad, when, you're not really putting in what you did to me to make me react like that!" Youth questioned the line between staff "doing their job," by recording the day's events, and as Gina said, "being fucking pissy," leaving youth little recourse to share their point of view. Staff could be dishonest about their part in a conflict and could exaggerate or validate staff perspectives with little recall for the youth's side of the story to be heard. Youth could complain, or fill out a formal grievance, but when they could not actually read the perspectives written in the comm log, the feeling of someone talking behind one's back, of gossip, mistrust, flavored youth's perceptions of the comm log.

Lastly, the comm log reinforced the hierarchy and structure of the quasi-total institution. When staff took time to write in the log every shift, they produced a reminder that they had access to the administration's ear and held the keys to how things were run. Whenever a staff asked youth to leave the office so that they could check in and take care of administrative tasks, including filling in the comm log, it reinforced to youth that beyond interacting and connecting, staff were watching them, and writing down their experience of what happened. As an example of a bureaucratic artifact with real power at Inanna House, the comm log preserved particular forms of hierarchy linking it to structural violence.

Mounted cameras provided another kind of surveillance Inanna House used to enforce disciplinary power. Outside, cameras were mounted on every side of the house as well as above every entrance door. Inside, mounted cameras directed their gaze at the hallways, office, kitchen, living room, and all bedroom doors. In "Kids Need Structure: 
Negotiating Rules, Power, and Social Control in an Emergency Youth Shelter," sociologist William T. Armaline writes,

Such physical structures and security measures are common to quasi-total institutions such as live-in social welfare agencies and increasingly for urban public schools. They serve to mark and monitor the physical external boundaries of the institutional space for the simultaneous purposes of internal social control and protecting internal populations from those seen as external threats (Armaline 2005, 13).

Cameras at Inanna House served this dual purpose, of watching for intruders outside and watching to enforce behavior compliance inside and brought to life Foucault's formulation of disciplinary power.

Youth all found the cameras on the outside of the house useful. Carmen, a 15 year-old white youth, explained, "They kept me safe actually because there was this one time when my pimp followed me to Inanna House and my pimp put a gun to my head and that got on that camera." Cameras inside the house, though, generated mixed feelings for the youth. Even though Gina made a game out of getting away with things on camera, cameras made her feel anxious and concerned about getting caught when she did things, like drugs, shelter rules prohibited. Despite knowing staff did not watch the cameras, or consult the video after an incident, Gina still internalized a version of the panopticon. The cameras' presence alone, even with no viewer, created a pressure mechanism for Gina to internalize the gaze and feel anxious, though not necessarily to discipline herself. When she knew she was really breaking an important rule, the presence of the cameras made her paranoid, but she still broke the rules and did drugs in the bathroom or her bedroom.

The camera with no viewer frustrated youth. An 18 year-old African American named Tonya said about the indoor cameras, "I'm glad the camera is there, however, they don't give a fuck about the fucking cameras! They don't even care, they didn't even sit 
down to actually look and see who did glue the piano shut, just shrug it off their shoulders." Being so blatant and direct about not utilizing the cameras drove home to the youth that the cameras served as a constant pressure of the, essentially unmanned, gaze. Another youth also asked for the staff to utilize cameras as a way to help enforce boundaries in the house.

Youth were not allowed to enter each other's rooms at any time. The most important reason for this rule was to prevent youth from engaging in sexual activity with each other, especially because this can lead to recruiting peers into prostitution. The rule also existed to prevent theft and to allow youth some privacy and space that belonged solely to them while they resided at Inanna House. Sometimes though, youth did enter each other's rooms when staff were not present or not watching the cameras that pointed at all the bedroom doors. One time, Gina put a plastic rat in Jackie's bed as a joke. Gina and Jackie were friends and Jackie knew it was a prank and not intended in malice. Instead of being angry at Gina, Jackie took issue with staff members failing to use the cameras to watch who came in and out of her bedroom door.

I came in to work the morning after the rat incident and the overnight staff person checked me in about what had happened. Jackie came to the office later in the morning and said, "Can you guys be more vigilant with cameras? No one should be going in my room. I'm gonna lock my door now, but no one should be going in there. You guys need to watch the cameras." Using a bidirectional gaze, Jackie requested not that her peer have better boundaries but that staff members use the cameras to watch events in the house more closely. Jackie and Tonya requested that staff use the cameras and therefore become both better at surveilling what went on in the house and, potentially, better at enforcing 
boundaries and acting as guardians of the youth's private space. Youth used the disciplinary technology of the cameras as a strategic mobilization of their own agency to involve themselves in the structuring paradigm within the house.

Bidirectional Gaze: A case study of the "Care Team"

In a bidirectional gaze, not only did staff watch youth, but youth also watched and influenced staff and the structures around them. This bidirectional gaze violates the principles of the Panopticon, where power should flow only in one direction. As it had in the instance of the plastic rat, this two-way disciplinary gaze also surfaced in the design of 'care teams.'

The principles guiding care teams formed a Venn diagram with the hierarchical, disciplinary relationships of total institutions. The concept of a care team challenged staff to impose disciplinary authority while also building supportive relationships based on ideas of trauma-informed care. Care teams consisted of two full-time staff members who helped advocate and cheerlead for a particular youth.

As usual at Inanna House, real and ideal structures differed. Using my notes from the field, I consider below the relationship between Stacy, a white 34 year-old full-time residential counselor, and Tonya an 18 year-old African American youth, that developed during the time I collected data. After working at Inanna House for three months, Stacy's supervisor finally assigned her to a care team with another staff member. Stacy had looked forward to this aspect of the job, where she had more responsibility to build relationship and mentor a youth. Responsibilities as a care team member included helping youth make and keep appointments with providers, communicate about productive time 
or other goals that would enable youth to move up stages for more privileges, and support the youth to grow more self-sufficient and ready to move on in life. Care teams also helped mediate conflicts between the youth and other staff.

Things started to go sideways, as they did at Inanna House, pretty quickly. First, events stalled Stacy's ability to start as a care team member, and then Tonya did not engage with the care team initiative. Stacy had first asked the supervisor about the care team a few weeks after she started working. But, due to canceled staff meetings, low residents in the house, and the supervisor not making supervision or check in time for this a priority, it took a few months for the supervisor to assign a youth to Stacy.

Once assigned to a care team, Stacy hoped to schedule a time to meet one-on-one with Tonya, but Tonya stayed in her room, perhaps sleeping, for Stacy's entire shift. Next time Stacy came in for her shift, she tried again. When she saw Tonya, she asked, "Want to go over some of your goals and stuff? I'd love to help you make it to your doctor's appointment on Tuesday and just get a chance to check in with you about anything else you need." Tonya replied curtly, "No thanks." Stacy realized that perhaps saying that she knew about Tonya's appointments, without Tonya telling her directly about them, may have affected her attempt at connecting with Tonya, who strongly guarded her private life.

Despite Tonya's negative response, Stacy persisted, choosing when to bring up the care team again and when to focus on building relationship by just chatting, giving space, or spending time watching TV together. To create a relationship that was not (only) disciplinary, Stacy utilized a trauma-informed approach and tried to respect Tonya's boundaries and to let the relationship evolve organically. Tonya resisted, though, 
by not engaging much with Stacy. Care teams, assumed to benefit the youth, also required youth to engage with staff, which for some youth felt like another reminder of the supervision, lack of freedom, and surveillance in their lives. Still, some youth appreciated the extra attention they got from their care team for a period of time. But Tonya did not want people "up in her business" and did what she could to keep things private so that every staff member did not know all the details about her life.

Even though Tonya did not engage much with Stacy, she knew Stacy was still observing her throughout her day. Tonya remained aware of the different ways she was being generally surveilled in the program. As a youth who resisted the opportunity for more relationship, she still demanded staff do their job. When they often failed to, Tonya gained leverage. For example, a couple months later, without any further openness on the part of Tonya to meet or engage with Stacy as a care team mentor, Tonya came into the office and asked Stacy how many more hours she needed that week to have enough productive time to move up stages. Stacy, without skipping a beat, looked it up on the computer, but Tonya said, "I thought you were supposed to already know that because you're on my care team." Tonya acknowledged Stacy as care team member for the first time, as a gatekeeper to information about her 'progress' in the program, while also implying that Stacy had not done her job well. Tonya turned the institutional practice of a care team into a way of disciplining her mentor who had not done the care team work well enough. She used the tactics of a total institution against a staff member who had tried to build a mentoring relationship. Tonya acknowledged her own embeddedness in the relationships that form at Inanna House between youth and staff at the same time used the instruments and prescriptions of a total institution strategically. 
Despite the failure of creating more connection through the care team initiative, an opportunity arose for a specific encounter between youth and staff, creating an opening for a bidirectional gaze. The bidirectional gaze upset the rationality of the quasitotal institution that used the technique of disciplinary power to enforce its aims. Perhaps Tonya resented the care team initiative because she avoided engaging with Stacy in that capacity and denied the care team to structure their relationship.

The need to balance Tonya's investment in this configuration of 'care,' as well as Stacy's approach to making connection, complicated the care team design. Perhaps, though, rather than resistance or resentment, Tonya wielded her gaze with disciplinary force toward Stacy, and highlighted a snapshot of becoming. For traumatized youth, the step to recognize and harness a bidirectionality, a relationship, is an important one. In her interview, Tonya said that what she most appreciated about Inanna House was,

Givin' me my own room and the fact that somebody is expecting your call. Like, at a certain time of hour, especially at night time. Cuz I feel like, if they expect that phone call and, knock on wood, if something actually happened to me, like, hold on she didn't call, she didn't show up...

Tonya's surprising use of the bidirectional gaze shows her not fully constrained or fully detached from her social worlds (Biehl and Locke 2017, 10). Tonya was not only resisting a disciplinary power, but in the same turn engaging a plastic power, and a relationship in which she was embedded.

\section{"Becoming" and the Labyrinth of Care}

Residential counselors at Inanna House often negotiated difficult circumstances and challenging behaviors. When staff members did not know how or why to enforce rules, they were not consistent with themselves or other staff members. Inconsistency 
lead to distress for youth; it signaled a lack of safety and unclear boundaries, both of which could be retraumatizing to CSE youth.

When trauma-informed care did happen at Inanna House, I argue that it happened through staff members both acting and relating more out of the elements of "becoming" than any clinically oriented ideas about trauma. "Becoming," as formulated by philosopher Gilles Deleuze (1997), refers to the ways in which people have dynamic and creative relationships with the world, relationships that are constantly unfolding, often in novel and surprising ways. At Inanna House, becoming happened in the moments when the organization of control faltered and failed and trauma-informed care offered no road map. Becoming happened in the ways staff and youth balanced, often delicately, the many pressures and roles of life with their own motivations and desires.

Biehle and Locke explain becoming by elaborating on three key dimensions: plasticity, desire, and the unknown $(2017,5)$. Plasticity reflects the malleability of the brain, the subject, and the social field. It acknowledges that power does form bodies, identities, and meaning but that people are not so much claimed by history as they are "makers of new systems of perception and action that come with specific sets of possibilities and limits" (Biehl and Moran-Thomas 2009, 277). Rather than viewing youth only through their trauma histories, plasticity considers people's agentive power. Lisa put it this way: "As a residential counselor, we are maid, enforcer, mother, therapist, and then still have to be transparent, and honest, and not lose patience, or our temper. We have to constantly be on this balancing beam." To remain on the balance beam meant fiddling with these many roles, sometimes making minor adjustments between positions, moving between mother and maid, and sometimes making fickle movements, like trying 
to be a transparent enforcer. At Inanna House, plasticity included people's ability to be slippery, inventive, and gritty, like Tonya in the example above.

Desire forms a second dimension to becoming. It emphasizes that, along with a plastic power not determined by the past, youth are also shaped by what they want for the future. Biehl and Moran-Thomas discuss the ways in which the theory of structural violence, or theories of trauma and trauma-informed care, view people "inescapably cast as subjects of memory" $(2009,277)$. Diverging from this view, becoming opens to the desires that disrupt the structural constraints that box people in. Becoming considers how people's inner lives may be less a subject of power and memory and more a subject of their desire. Biehle and Moran-Thomas write:

Whether in social abandonment, addiction, or homelessness, life that no longer has any value for society is hardly synonymous with a life that no longer has any value for the person living it.... Against all odds, people keep searching for contact and for ways to endure, at times reworking and sublimating symptoms in their search for social ties $(2009,281)$.

Further, desire redirects care to the youths' strengths and their insights about themselves and their future.

Gina was not only shaped by, and living within, the context of her present and past — doing sex work in motels and, as she told me in our interview, getting high on meth to do so. She was also, admittedly perhaps sometimes more and sometimes less, shaped by the desire of a wider world. Gina spoke about beginning an experimental study using a new drug to get off meth. She often would speak about rescuing different animals and the care she gave them. She dreamt of having a small property where she could foster abused animals. Both the past and present are open and indeterminate because desire “does not seek a singular, decontextualized object, but a broader world or set of relations 
in which the object is embedded and becomes meaningful," write Biehle and Locke $(2017,6)$. Desire in the context of becoming champions the fact that what people desire is more than doing meth or having a farm but in fact a world that is interconnected and meaningful. When Gina lived at Inanna House, she sought meaningful connections with staff members and peers. These connections existed alongside relationships with clients she knew through sex work. Becoming allows trauma-informed care to find a place to land; beyond understanding historic reasons for current behaviors, the whole person embedded in a layered social world comes into view.

Further, becoming involves an attentiveness to the unknown; "Unfinishedness is integral to becoming," Biehle and Moran-Thomas write $(2009,277)$. Becoming involves a constant tinkering, animating the present into the future to leave behind what is known and step into the incompleteness of one's life. Becoming includes the messiness of lived experience, where "the human subject is not an autonomous, rational individual or a stable self but an always unstable assemblage of organic, social, and structural forces and lines of flight that at once shape and are shaped by their milieus" (Biehl and Locke 2017, 8). Becoming thus acknowledges the negotiation between the unfinishedness of youths' stories and the uncertainty that permeates life, both inside and outside a crisis shelter. Amidst the disciplinary power and social control of a quasi-total institution, becoming and its dimensions of plasticity, desire, and unfinishedness highlights how traumainformed care actually happened and what it felt like at Inanna House - the chaos, intimacy, and tangle of so many moving parts.

Moreover, becoming happened in the proximity of youth and staff within the shelter. Staff and youth spent extended periods of time together day after day, sharing 
meals, doing mundane things like shopping for groceries and going on cigarette runs, driving around with music blaring, and swimming together at the pool. Youth asked staff to wake them in the morning and to give them their night meds or melatonin before they went to sleep. Gilles Deleuze writes about the role of proximity in his conception of becoming. He writes, "To become is not to attain form but to find the zone of proximity... unforeseen and non-preexistent, singularized out of the population rather than determined by a form" (Deleuze 1997, 1). Rather than viewing youth through a label of "commercially sexually exploited" or "traumatized," trauma-informed care as becoming actually happened when staff members allowed youth to be unique individuals. Then, as individuals, an interconnectedness occurred, shedding the formality of 'staff' as enforcers or as experts of trauma. Ideas of best practices, trauma informed care, how one should or should not act, and the positionality of authority were all transformed. When this closeness happened, a deep relatability took place. By their closeness, sharing meals and movies, staff members and residents reworked in practice the formal ideas of staff members as enforcers with a monopoly on the disciplinary gaze.

The complexity of working and living at Inanna House implored people to engage as people becoming. As Lisa said, "This population, they're not just like teenagers, they're not just adults, they're not just children — they're all of it at different times— at all times! So it's like a constant— trying to read where everyone's at." Staff members had to assess in each moment, who is this youth right now? Who am I? Who should I be right now? Staff and youth engaged creatively with each other's desires, while also negotiating the pressures of their social positions within the house. As Grace said, "You never know what's gonna happen, but it's always good to give people a chance." Care was repeatedly 
only possible in the space of flexibility, possibility, and openness, in particular because control was so fleeting.

In conclusion, the creativity of staff to manage their opposing roles and express care, as well as the playful surprising ways youth acknowledged and influenced their relationships with staff members and structure alike eroded institutional attempts at Inanna House to modify, regulate, and control the behavior of both youth and staff members in certain ways. At the same time, trauma-informed care surfaced precisely where the total institution broke down and the mutuality of closeness and unfinishedness of becoming took place. Becoming "always happens in the 'middle': people moving along and amid multiple lines, pushing the boundaries of forms" (Biehle and Locke 2017, 15). Because the boundaries of disciplinary power and total institutions dissolved due to poor supervision, lack of training, and high staff turnover, more becoming was possible. And ultimately, through becoming, trauma-informed care emerged. Through youth being recognized as more than their experiences, more than their actions even, they got a unique opportunity to follow more freely their many desires.

The experiences of Inanna House I have discussed in this chapter suggest a new paradigm is required to serve the needs of CSE youth. I will present some reflections and suggestions for further research in my concluding chapter. 


\section{CHAPTER 5: Conclusion}

$\underline{\text { Hue }}$

We are all dealing with the same crimson, carnelian, burgundy, brick, blood, cinnamon, rose, fire-

Or is it we all dance in brass, dance in amber-

We are all swimming in jade, in jungle, swimming in mint, sinking in hunter, olive, moss, myrtle, fern-

Or is it we all sweat in violet, in lava, sweat in smoke-

We are all thinking opal, dreaming lavender, lemon, forgetting and forgetting baby blue-

Or is it we all hope in royal purple, hope in gold-

We are all down to our last russet, saddle, roast, root, pearl, down to our last, to our last, our last pig, pine, silver, salmon-

Or is it we all worry satin, scarlet, sangria, saffron, sage-

Coral, cobalt, carmine, corn, copper, ghost white, granite, gunmetal, glacier, coal.

\section{Jackie and the Piano}

Most youth had trouble sleeping at night. Some would get stuck with thoughts of 'The Life' when they were trying to fall asleep, or they would fall asleep and then wake up in the middle of the night with those thoughts. Grace, who worked graveyard shift, said she would empathize with a youth who came into the office in the middle of the night. She said she would tell them, "I know it's toughest at night, cuz you're used to bein' out. Mommy's here." Some youth took melatonin to help them sleep. Others read, organized their room, or listened to music. Sometimes, by early morning, sleep came; sometimes, youth would not be able to sleep until the afternoon. In the context of 
wrestling with the triggers associated with night time and sleep, morning noise, like the playing of the piano, was a problem for those youth who had trouble sleeping during the enforced quiet hours of the program, from 11 p.m. at night to 7 a.m. in the morning.

One day while I was working, Jackie, an 18 year-old Hispanic and Native American youth who had been accessing services at Inanna House since she was 14, struggled with noise disrupting her already difficult time trying to sleep. She came in to the office doorway around 10 a.m., clearly distraught. She spoke with tight breath, her voice pitched high and her words caught, pleading through the stress that was clearly palpable. "Why can't I just sleep?" she said, with a whine that made clear her exhaustion. "I'm so tired and all I want to do is just sleep, please, why can't I just sleep?" She was almost crying. She came into the office and sat down. "I just wanted a couple hours. Why does she have to play the fucking piano? It's right next to my door. I asked her, but no one listens to me. I couldn't sleep all night until 8 a.m....”

I was sitting at the staff computer and responded, "I'm really sorry. That sucks. What can I do for you? That sounds really frustrating." Jackie paused emotionally for a moment— she was quiet, resting. Then she said, "I want to call Marcy." Marcy was the case manager; she had known Jackie for five years. I dialed the number, asked for Marcy, and handed the phone to Jackie.

Immediately Jackie started crying, "I can't stand this anymore! No one will fucking stand up to her! I'm begging you, please do something about the quiet time hours. This is not how the real world works. She needs to be told to respect other people's needs." Marcy asked some clarifying questions and then responded, saying that quiet time ends at 7 a.m. and the other youth was not doing anything against the rules. 
Marcy explained that quiet time hours probably would not change, but Jackie could write a grievance and talk to the program director about changing the rules. From crying, Jackie's emotions turned to frustration and anger at Marcy's response. She hung up on Marcy abruptly.

I asked, "What did she say?" "She's a stupid fuckin idiot," Jackie replied. She then went into the kitchen and made herself some breakfast. Returning to the office, Jackie began talking again about her frustrations. She shared that she was feeling bullied by Tonya, the youth who was playing the piano earlier that morning. She told me that she felt unsupported, told to go to a higher up with the conflicts she had with other youth, and getting shut down when she did try to elicit the advocacy she felt was missing. The supervisor told her to handle interpersonal difficulties directly with other residents of the house, suggesting Jackie talk to Tonya directly about not playing the piano in the morning. Though Jackie and Tonya used to be close friends, their relationship had deteriorated.

When I spoke to the supervisor about the issues around quiet time, she restated the expectation that staff are not there to negotiate the interpersonal drama of the youth for them. The supervisor highlighted that Inanna House was a shelter, and not a rehabilitation program; further, the supervisor emphasized that it was not the staff's role to fix every problem the youth had with each other.

Later in the morning, the program director stopped by the house to pick up Keisha for an appointment. Seeing the director, Jackie's feelings of anger flared. Speaking in an accusatory tone, she said,

How would you like it if someone was playing piano when you were trying to sleep? I'm going to come to your house, watch how you like it. I'm going to 
come to your house and play a piano really loud right in front of your door at 8 in the morning. If you don't change the rules, I'm going to show you how it feels.

Jackie got worked up quickly. She leaned forward in her seat, the volume of her voice rose, and she pointed at the director occasionally. The director fumbled through the exchange, restating the rules, restating the option of writing a grievance, and also saying she had no piano at her house. As the director was leaving with the other youth and the door was closing, Jackie yelled out a string of profanity, calling the director names, cursing her intelligence, her looks, the way she spoke, and her history with the program and her current role as director.

Next, Jackie decided to follow the protocol and write a grievance letter. As she worked on her letter, she told me this was the third time in a week she had an issue with Tonya playing piano in the morning. Jackie was overwhelmed and exasperated that staff did not listen to her in the first two instances, not following up on mediating a compromise or conversation between the youths. Further, when she tried to do what the staff asked of her, to negotiate interpersonal conflict on her own, she felt snubbed again because Tonya continued to play the piano after Jackie's request. She felt like no one cared about her needs, and that no one thought her sleep was important.

How could Jackie have gotten the care she needed? If someone had the energy, and took the time to mediate between her and Tonya, what could that have done for each of them? And for the feeling in the whole house? This example highlights the ways the quasi-total institution had established ways to shift responsibility, both on the individual staff level and as a whole, and this put barriers in place for Jackie to get her needs met in any number of small moments she felt unseen and uncared for by the program. Jackie's 
story here offers another example of a traumatropism, alongside her yearning for people to deeply relate to her basic need for sound sleep.

Jackie ended up getting kicked out a couple weeks later because she threw a small box in the office and it hit a staff member's leg. She was permanently exited from the program and could not return to access Inanna House services in the future. Could the incidents around noise and sleep have been an opportunity to change that course of events? Could mediation have helped Tonya, who became more defensive and isolated in the house because of her piano playing?

If Inanna House wanted to help youth who have had experiences of commercial sexual exploitation, then why was it unable to help this youth? Or did it help this youth? Did it help youth to have a place to go away from a trafficking situation? Did it help them heal? Perhaps it was meant as a stepping stone towards healing but not the place to do that healing. Was it driven only by the need for fewer youth to be found on a night of an FBI sting? In the many ways the existence of a shelter for CSE youth helped those youth, the shelter also did some harm. To gain access to the care Inanna House provided, to shelter, food, and clothing, youth had to abide by rules that were constraining, that reinforced feelings of oppression and powerlessness.

Inanna House left residents feeling like they lived in a chaotic place reminiscent in some ways to the living arrangements which they left to seek shelter there. The flaws of the quasi-total institution raises the question of what could serve CSE youth better. Rather than suggesting that the house should become better at holding totalizing parameters, I think this data about Inanna House suggests that a new paradigm is 
required, a program design that better fosters feelings of stability, both for youth and the staff.

Thrown into this mix, the appeal for trauma-informed care floundered. When trauma-informed care surfaced, plasticity, desire, and the unknown came to the fore. When the framework of rules malfunctioned and disintegrated, staff and youth were forced again and again into an uncertain, slippery space. I argue that through becoming trauma-informed care endured the pressure chamber of Inanna House's dysfunctional structure. Staff showed they cared by approaching the youth as though they were people who were changing, desiring, unknown, and unfinished. Trauma-informed care developed where staff made more space for the youth to change, desire, and unfold into their life beyond their history of trafficking.

Without firm reference for the rationale and coherence of what it was that was happening at Inanna House, becoming surfaced as its own structure, with its own rationale, in which to relate. I argue that care happened because staff and youth had this other structure of becoming - open ended, inventive, and capable of making novel connections. If the total institution functioned smoothly, if disciplinary power and surveillance were enforced with exacting focus, (if this sort of structure is even possible at all), then certainly care of this kind, that allowed people to change, would not be possible. Perhaps trauma-informed care could not happen at all. Ironically, instead of the behavior modification techniques of discipline, using the model of becoming opened the door onto an unfinished world where change seemed more possible.

\section{Continuum}


An organization like Inanna House might situate their approach to CSE youth recognizing the structural and symbolic violence youth experienced before exploitation and design services for them that recognize the structural and symbolic violence that happens in their everyday lives. This could include higher wages and better benefits for the staff. If staff are not personally struggling financially, they may be able to provide more stable care, creating a vision for the youth that they also may find some financial stability. Inanna House missed taking account of the ways in which personal experiences flow out of economic structures. Further, the board of directors and executive director overseeing Blue Sky Youth Programs failed to take account of the ways the organization functioned in a complete helter skelter as traumatized as its clients, but with a dangerous history of power and righteousness about behavior and control at its back.

Trauma-informed care must include a critical examination of the pathologizing of suffering that falls heavily on the socially vulnerable. Arthur Kleinman describes the violence continuum as a way to extend the concept of political violence to a concept of social suffering, "the devastating injuries that social force inflicts on human experience" (Kleinman 1997, 226). To take account of structural and symbolic violence, human service agencies might benefit from even more avenues to listen to how and what meaning their clients make about their own lives. Gina critiqued what she felt was a patronizing organization of care that "overthinks itself." She advocated for herself as someone who was more than herself when she was high, more than someone else's best intentions for her, and more than what they think is in her best interest.

The continuum of violence also extends the concept of political and social suffering to the somatic and mental realm. Seeing violence as a continuum allows us to 
connect the extraordinary and the ordinary, the out of body and the embodied. Using a continuum model lends itself to breaking out of a Cartesian dualism of mind and body, and supports a holistic approach to healing, where healing is not only situated in one place, not only in one individual, but in the collective as well.

\section{Tipping Point}

The shelter and residential program at Inanna House reached a critical tipping point at the end of my time conducting research there. Over the course of the previous two years, three groups of full-time staff, two supervisors, and three directors cycled through positions within the organization and contributed to a final programmatic collapse. During the last month of my research, I worked as 'relief coordinator' scheduling relief staff or filling in if no one else could pick up the open shifts. Over the two weeks I worked, the program was down seven staff. For a 10-day period during this time, both the director and case manager were away on vacation. The supervisor was out indefinitely on long term medical leave. Five full-time residential counselors were outthree had quit at the same time, and two were on family and personal medical leave. I worked over 100 hours over the course of two weeks.

In December, two months after my two-week shift as relief coordinator, the county pulled the funding for the program. Inanna House had been open for 7 years. Willamette Weekly printed an article titled "A Portland Shelter Meant to Help Sexually Trafficked Teenagers Instead Drove Them Into the Street." Katie Shepard wrote:

The county ran out of patience last month...Records show county officials began warning Blue Sky in mid-2016 that the program wasn't reaching enough clients, and had failed to meet goals to get most of the home's residents in school, job training and stable housing. 
Blue Sky Youth Programs requested from the county two months for the transition, closure at the beginning of December, or right after Christmas, was just too harsh. No new youth were admitted in the meantime and the youth who were living at the shelter had to find other emergency or transitional housing or become homeless when Inanna House closed. The remaining full-time staff members lost their jobs.

After news of the Inanna House shut down had been made official, Blue Sky Youth Programs held one last all staff meeting. As I entered the large cold room where the meeting was held, a palpable grief could be felt. Waiting for the meeting to start, staff gathered in small groups, not talking very much, faces flat, sad, and defeated. The weight of knowing that the youth could not access emergency shelter in their times of need anymore and that the relationships with youth fostered through Inanna House would end, sat heavy for everyone present, for direct care staff most of all.

\section{$\underline{\text { Grief Encounter }}$}

By working as a residential counselor for two years and by doing ethnography, observing, reflecting, interviewing, and analyzing youth and staff experiences at Inanna House, I came to focus on the relationship between social control (the rules) and a plastic power (becoming). I observed the way both youth and staff inserted their intra- and interpersonal selves into the structures around them. More fundamentally though, I found myself confronted time and again with the shadows commensurability and incommensurability cast on each other at the shelter. In the context of a social commensurability I became, and continue to become, intimately woven into the work of 
this ethnographic thesis, the work of being a resident counselor, and the work of being human.

The time I spent working and then conducting research at Inanna House was transformative for how I myself grappled and processed my own trauma, and how I have come to understand the glimpses of what I saw as good in the often devastating messiness of that place. I realize that there is a possibility that by bringing my personal voice forth, the youths' voices may be overshadowed. I do not want the things that I gained from Inanna House to then be projected onto or assumed about what the youth may have gained. I do not want my personal experience at Inanna House to deny the perspectives and experiences of the youth I worked with, taking into account my position of considerable privilege in relation to the residents at Inanna House. I think that it is worthwhile, though; in fact, I think that it is imperative, that I am upfront and candid about how the encounter with these youth changed me, at this shelter designated for minor survivors of sex trafficking. Even though we are not the same, across all of our difference, across all of our uneven distribution of difficulty, pain, and economic access, our encounter changed me, and I glimpsed our encounter changed the youth as well.

Being changed does not mean that much in a lot of ways. I would not say that the changes, the effect we had on each other, is connected to justice per se; it is not effecting the structures of race, class, or gendered oppression. Perhaps, though, registering and attending to moments of deep relatability we shared at Inanna House points to what is wrong with and missing from oppressive paradigms. Perhaps attending to deep relatability offers the new foundation needed from which to build other worlds. White anti-racism author and educator Tim Wise astutely observes, "One of the things white 
supremacy required of white people was the death of empathy. Only by causing us to numb ourselves to the pain of others could otherwise decent people (which most white folks are) collaborate with such a monstrous system" $(2012,23)$. The perspective I discussed in Chapter 2, of the structural and symbolic violence and historical roots connected with the present existence of a shelter for commercially sexually exploited youth, offered a glimpse into some of the processes that played a part in structuring and institutionalizing this numbing.

Further, when we numb ourselves to the pain of others, we also lose the ability to grieve their pain. Perhaps losing our ability to grieve is not a problem, except that the ability to grieve unveils our embodied interconnection, for it actualizes our recognition of the Other through the welling of our tears. Without grieving we lose our human bearings. Judith Butler writes,

Is there something to be gained from grieving, from tarrying with grief, from remaining exposed to its unbearability and not endeavoring to seek a resolution for grief through violence? Is there something to be gained in the political domain by maintaining grief as part of the framework within which we think our international ties? If we stay with the sense of loss, are we left feeling only passive and powerless, as some might fear? Or are we, rather, returned to a sense of human vulnerability, to our collective responsibility for the physical lives of one another (Butler 2004, 30)?

I bring the question of grief up here because without fostering my relationship with grief while working, doing research, and then writing about Inanna House, I would have been overwhelmed beyond my capacity to engage with the complex realities of our world (Weller 2015). Making contact with the things that touched me deeply, paying attention to grief rather than ignore it, made a difficult world more bearable. When I suppressed my emotions, I became frozen, shut down, stuck. Violence can be hard to comprehend 
mentally but feeling heartbroken that people experience violence can make sense straight to the gut and helps reconnect with the body in the present moment.

Moreover, cultivating a relationship with grief allowed me to comprehend my own pain and vulnerability. By comprehending my pain, I gained the firm fact of the Other, for it was because of the Other that I came to be in pain. Grief was the balm to soothe my shame. Instead of identifying with the pain of violence done to me, I could lament it. Grief allowed me to separate who I was, from what had happened to me. I understand myself through this wrestling with grief, and in so doing understand Inanna House and its residents and staff through the lens of this relationship with grief.

I came to wonder if what was missing at Inanna House was a sense of grief that was not based on an understanding of vulnerability as victims needing rescue, but an acknowledgement of our own fundamental human vulnerability, yours, the youths', and mine. Our bodies are already hardwired to know this personal vulnerability. Our brain and body have tools for survival that engage when we are faced with the perceived or real threat of injury and death.

The organizers of care at Inanna House were unable to discern between the care of commensurability as gaze and the care of commensurability as relatability. Commensurability as gaze identified with someone's suffering by othering them, understanding someone's pain through our differences, shutting down to our own vulnerability by projecting vulnerability only onto someone needing to be 'rescued.' Deep relatability, on the other hand, related with the suffering of others through our own pain and vulnerability, and through the tender disorientation of our own grief.

Further Research 
Through the dynamic processing of emotions, thoughts, experience, and knowledge that I synthesized for this thesis project, I hoped to create more space in research for the subject and subjects of domestic minor sex trafficking. At the same time, I created that space in research through embodied relationships with those youth. The question of whether someone else is present can raise the question of whether I am present. It is not only the subjects of my research, but me myself, and perhaps by extension the reader in some way, who participate in the constituting of these relations (Butler 2015, 12). I attempted to bring the voices of youth, as well as direct care staff, to the forefront in this study, adding to the research done directly with minor survivors of sex trafficking in the United States. More research centering youth and direct caregivers' voices is needed.

CSE services may also benefit from further consideration of how the demographics of staffing impacts youth. More evidence-based research is still needed on the impact on youth of having survivors and people of color as therapists, supervisors, and directors of organizations. In addition, research on the impact of wage on crisis care providers and how wage impacts services for people in crisis would be highly recommended.

I attempted to highlight the ways in which youth, as well as direct care staff, had ideas and desires of how to manage and shape their own lives in the context of the shelter. A number of youth spoke in their interviews about wanting the program aspect of Inanna House to be more individualized, and the shelter aspect of Inanna House to have fewer strings attached. Youth have creative ways to express new ideas for their care, and 
dysfunctional service systems may benefit greatly from developing new ways to see, hear, and feel youth's ideas of care.

Youth at risk carry the brunt of fluctuation in advocacy and funding, exposed not only to pimps and johns, but also vulnerable because of inconsistent services of care available. If services were not built as much on the premise of 'rescue' for victims but more on celebrating survivors' strengths, and youth were deemed worthy of 'protection' not because they are innocent but because they are wise, perhaps care would become more stable and more far reaching. More research is needed to help support programs find better ways to meet youth where they are at, honoring their dynamic toolkit of survival skills and their own vision and understanding of their lives.

\section{Matrix of Relationships}

Finally, Inanna House raised vital questions about human connection and the many realms of relationship. From pain, caused by the people and systems that commercially sexually exploit youth, comes the implication of the collective, including the people and systems that come to label and rescue them. Considering the ways in which people who are traumatized make a way back toward the whole that was consigned to the fragmented part during dissociation, make their way back in to relationship, we find that violence is very closely threaded with a deep sense of belonging. This belonging to one's own body, to a network of relationships, also includes life's belonging to death, death's belonging to life. Through the space of Inanna House, a novel frame of relationship formed. Judith Butler writes, "It might be that the constituting relations have a certain pattern of breakage in them, that they actually constitute and break us at the 
same time" (Butler 2015, 9). In fact, it might be that "matrix of relations" that both constitute and break us, forms us as subjects. It was through this dynamic matrix that each of us was unfolding at Inanna House, especially the people who were with the youth day in and day out, who shared meals, movies, car rides, and bedtime with them. Each of us became an "I," a "You," and Inanna House a place marker for a tentative "We." Youth and staff shared an immediacy there, a presence, a "Here we are."

\section{$\underline{\text { I Love You }}$}

I met Gina for our interview at a park, two weeks after she had been exited permanently from Inanna House. The morning of our interview, she had just returned to her mother's house after a week doing sex work and meth at a motel. We sat in the park for more than an hour, talking and playing with my dogs, who I had brought because I knew she loved animals. At the end of the interview, I walked her back to her mother's house and she asked to give me a hug. "I love you," she said, as she turned to go. I was struck. Then, breaking my freeze, I replied, "I love you too." 


\section{Bibliography}

Adams, Erica J. 2010. "Healing Invisible Wounds: Why Investing in Trauma-Informed Care for Children Makes Sense." Georgetown University: Justice Policy Institute.

Arendt, Hannah. 1970. On Violence. New York: Harcourt, Brace, Jovanovich.

Armaline, William T. 2005. "Kids Need Structure: Negotiating Rules, Power, and Social Control in an Emergency Youth Shelter." American Behavioral Scientist 48 (8): 1124-48. https://doi.org/10.1177/0002764204274196.

Beyerlein, Brittany and Block, Ellin. 2014. "Need for Trauma-Informed Care within the Foster Care System: A Policy Issue."

Bernstein, Elizabeth. 2010. "Militarized Humanitarianism Meets Carceral Feminism: The Politics of Sex, Rights, and Freedom in Contemporary Antitrafficking Campaigns." Signs: Journal of Women in Culture and Society 36 (1): 45-71. https://doi.org/10.1086/652918. . 2012. "Carceral Politics as Gender Justice? The 'Traffic in Women' and Neoliberal Circuits of Crime, Sex, and Rights." Theory and Society 41 (3): 23359. https://doi.org/10.1007/s11186-012-9165-9.

Biehl, João Guilherme, and Peter Andrew Locke, eds. 2017. Unfinished: The Anthropology of Becoming. Durham: Duke University Press.

Biehl, João, and Amy Moran-Thomas. 2009. "Symptom: Subjectivities, Social Ills, Technologies." Annual Review of Anthropology 38: 267-288. http://www.jstor.org.proxy.lib.pdx.edu/stable/20622653.

Birckhead, Tamar R. 2011. "The 'youngest profession': consent, autonomy, and prostituted children." Washington University Law Review 88 (5): 1055+. Business Collection.

Blau, Gary M., Beth Caldwell, and Robert E. Lieberman. 2014. Residential Interventions for Children, ADolescents, and Families: A Best Practice Guide. New York: Routledge.

Bloom, S. 2006. "Organizational stress as a barrier to trauma-sensitive change and system transformation." Alexandria, VA: National Technical Assistance Center for State Mental Health Planning Publications and Reports.

Bloom, Sandra L., and Farragher, Brian J. 2011. Destroying Sanctuary : The Crisis in Human Service Delivery Systems. New York ; Oxford: Oxford University Press.

Bourdieu, Pierre. 1977. Outline of a Theory of Practice. Cambridge Studies in Social Anthropology ; 16. Cambridge ; New York: Cambridge University Press. 
Bourgois, Philippe, and Corinne Hewlett. 2012. "Théoriser La Violence En Amérique: Retour Sur Trente Ans D'ethnographie." L'Homme, no. 203/204: 139-68. https://www.cairn.info/revue-1-homme-2012-3-page-139.htm

Brennan, Denise. 2014. Life Interrupted: Trafficking into Forced Labor in the United States. Durham: Duke University Press.

Brubaker, R., and Cooper, F. 2000. "Beyond "Identity"." Theory And Society,29(1), 1-47.

Butler, Judith. 2006. Precarious Life: The Powers of Mourning and Violence. London; New York: Verso. 2015. Senses of the Subject. New York: Fordham University Press.

Caruth, Cathy. 2007. Unclaimed Experience: Trauma, Narrative, and History. Nachdr. Baltimore, Md.: Johns Hopkins Univ. Press.

Chateauvert, Melinda. 2014. Sex Workers Unite: A History of the Movement from Stonewall to SlutWalk. New York: Beacon Press.

Chaudhry, Lubna Nazir. 2004. "Reconstituting Selves in the Karachi Conflict: Mohajir Women Survivors and Structural Violence." Cultural Dynamics 16 (2-3): 25990. https://doi.org/10.1177/0921374004047751.

Chesney-Lind, M., and Shelden, Randall G. 2014. Girls, delinquency, and juvenile justice (4th ed.). Chichester, West Sussex: John Wiley \& Sons.

Clawson, Heather and Lisa Goldblatt Grace. 2007. "Finding a Path to Recovery: Residential Facilities for Minor Victims of Domestic Sex Trafficking." Human Trafficking: Data and Documents, Paper 10. http://digitalcommons.unl.edu/humtraffdata/10

Crenshaw, Kimberle. 1991. "Mapping the Margins: Intersectionality, Identity Politics, and Violence against Women of Color." Stanford Law Review 43: 1241-99.

Crenshaw, K.W., P. Ocen, and J. Nanda. 2015. "Black Girls Matter: Pushed Out, Overpoliced and Underprotected." African American Policy Forum, Columbia Law School Center for Intersectionality and Social Plicy Studies.

Coccoma, Patricia and Evans, Amanda. 2014. Trauma-Informed Care: How Neuroscience Influences Practice.

Conti, Megan. 2018. "Thinking Critically about Sexual Trauma in the 21st Century." In The Social Work and Sexual Trauma Casebook: Phenomenological Perspectives. Edited by Jaffe, Miriam, Floersch, Jerry, Longhofer, Jeffrey, and Conti, Megan. London: Taylor and Francis. 
Cusack, Carmen M. 2015. Laws Relating to Sex, Pregnancy, and Infancy: Issues in Criminal Justice. Basingstoke: Palgrave Macmillan. http://www.palgraveconnect.com/doifinder/10.1057/9781137505194.

Deleuze, Gilles. 1997. Essays Critical and Clinical. Minneapolis: University of Minnesota Press.

Empey, LaMar Taylor. 1982. American Delinquency: Its Meaning and Construction. 1982 rev. ed. The Dorsey Series in Sociology. Homewood, Ill: Dorsey Press.

Espeland, Wendy Nelson, and Mitchell L. Stevens. 1998. "Commensuration as a Social Process." Annual Review of Sociology 24 (1): 313-43. https://doi.org/10.1146/annurev.soc.24.1.313.

Estes, Richard J, and Neil Alan Weiner. 2001. "The Commercial Sexual Exploitation of Children in the US, Canada and Mexico." University of Pennsylvania, School of Social Work, Center for the Study of Youth Policy.

Farmer, Paul. 1996. "On Suffering and Structural Violence: A View from Below." Doedalus: Journal of the American Academy of Arts and Sciences 125 (1): 26183.

Feldman, Allen. 2015. Archives of the Insensible: Of War, Photopolitics, and Dead Memory. Chicago: The University of Chicago Press.

Fisher, Janina. 2001. "Dissociative Phenomena in the Everyday Lives of Trauma Survivors." Paper presented at the Boston University Medical School Psychological Trauma Conference.

Foucault, Michel. 1977. Discipline and Punish: The Birth of the Prison. 1st American ed. New York: Pantheon Books.

- 1979. Discipline and Punish: The Birth of the Prison. New York: Vintage Books.

Freedman, Estelle B. 2013. Redefining Rape: Sexual Violence in the Era of Suffrage and Segregation. Cambridge, Massachusetts: Harvard University Press.

Garcia, Angela. 2010. The Pastoral Clinic: Addiction and Dispossession along the Rio Grande. Berkeley: University of California Press.

. 2015. "Serenity: Violence, Inequality, and Recovery on the Edge of Mexico City." Medical Anthropology Quarterly 29 (4): 455-72. https://doi.org/10.1111/maq.12208.

Gibbs, Deborah A., Jennifer L. Hardison Walters, Alexandra Lutnick, Shari Miller, and Marianne Kluckman. 2015. "Services to domestic minor victims of sex 
trafficking: Opportunities for engagement and support." Children and Youth Services Review.

Goffman, Erving. 1961. Asylums: Essays on the Social Situation of Mental Patients and Other Inmates. Chicago: Aldine.

Google. 2019. "A Pathway to Freedom: Rescue and Refuge for Sex Trafficking Victims." n.d. Accessed April 28, 2019. https://www.govinfo.gov/content/pkg/CHRG114hhrg94608/html/CHRG-114hhrg94608.htm.

Goode, Starr. 2016. Sheela na gig: The Dard Goddess of Sacred Power. Vermont, Inner Traditions.

Goodey, Jo. 2008. "Human Trafficking: Sketchy Data and Policy Responses."

Criminology \& Criminal Justice 8 (4): 421-42.

https://doi.org/10.1177/1748895808096471.

Gordon, Linda. 1994. Pitied but Not Entitled: Single Mothers and the History of Welfare, 1890-1935. New York : Toronto : New York: Free Press ; Maxwell Macmillan Canada; Maxwell Macmillan International.

Hopper, E. K., Bassuk, E. L., \& Olivet, J. (2010). Shelter from the storm: Traumainformed care in homelessness services settings. Open Health Services and Policy Journal, 3, 80-100.

Hughes, Dhana. 2013. Violence, Torture, and Memory in Sri Lanka: Life after Terror. Routledge/Edinburgh South Asian Studies Series. London; New York: Routledge.

Kardimar, Skanda, and Kate Zen. "New York Activists Are Leading the Charge on Sex Work Decriminalization." June 2019. https://truthout.org/articles/new-york-activists-are-leading-the-charge-on-sexwork-decriminalization/

Kenny, Maureen, Haiying Long, Dawn Thompson, and Alejandro Vazquez. 2017. "Implementation and Program Evaluation of Trauma-Informed Care Trainging Across State Child Advocacy Centers: An Exploratory Study." Children and Youth Services Review. Elsevier.

Kessler, Glenn. 2015. 'Fact Checker: The Claim That 300,000 US Children Are 'at Risk' of Sexual Exploitation." Washington Post. http://ink.galegroup.com.proxy.lib.pdx.edu/apps/doc/A415437941/ITOF?u=s118 $5784 \&$ sid $=\mathrm{ITOF} \& \mathrm{xid}=4471 \mathrm{fb} 44$. 
Kim, Mimi E. "From Carceral Feminism to Transformative Justice: Women-of-color Feminism and Alternatives to Incarceration." Journal of Ethnic \& Cultural Diversity in Social Work 27, no. 3 (2018): 219-33.

Kivett, Douglas D., and Carol A. B. Warren. 2002. "Social Control in a Group Home for Delinquent Boys." Journal of Contemporary Ethnography 31 (1): 3-32. https://doi.org/10.1177/0891241602031001001.

Kleinman, Arthur, Veena Das, and Margaret M. Lock, eds. 1997. Social Suffering. Berkeley: University of California Press.

KM, Leslie. 2008. "Harm reduction: An approach to reducing risky health behaviours in adolescents." Canadian Paediatric Society, Adolescent Health Committee, Paediatrics \& Child Health 13 (1): 53-56. https://doi.org/10.1093/pch/13.1.53.

Koyama, Emi. 2012. "Youth vs. the Social Service Industrial Complex: How AntiTrafficking Hysteria Is Dismantling Harm Reduction Movement." Harm Reduction Conference. https://harmreduction.org/wpcontent/uploads/2013/01/YouthVsSSIC HRC Public.pdf

Kusmaul, Nancy, Bincy Wilson, and Thomas Nochajski. "The infusion of traumainformed care in organizations: Experience of agency staff." Human Service Organizations: Management, Leadership \& Governance 39, no. 1 (2015): 25-37.

Lancaster, Roger N. 2011. Sex Panic and the Punitive State. California: University of California Press.

Law, Victoria. 2019. “Against Carceral Feminism.” n.d. Accessed February 27, 2019. http://jacobinmag.com/2014/10/against-carceral-feminism/.

LeBel, Janice and Neil Kelly. 2014. "Trauma-Informed Care.” In Residential Interventions for Children, Adolescents, and Families: A Best Practice Guide. Edited by Blau, Gary M., Beth Caldwell, and Robert E. Lieberman, 78-95. New York: Routledge

LeCompte, Margaret Diane, and Jean J. Schensul. 2013. Analysis and Interpretation of Ethnographic Data: A Mixed Methods Approach. 2nd ed. Ethnographer's Toolkit, Book 5. Lanham: AltaMira Press.

Lerum, Kari, Kiesha Mccurtis, Penelope Saunders, and Stéphanie Wahab. 2012. "Using Human Rights to Hold the US Accountable for Its Anti-Sex Trafficking Agenda: The Universal Periodic Review and New Directions for US Policy." Anti-Trafficking Review: Issue 1. 
Lester, Rebecca. 2013. "Back from the Edge of Existence: A Critical Anthropology of Trauma." Transcultural Psychiatry 50 (5): 753-62. https://doi.org/10.1177/1363461513504520.

Lloyd, Rachel. 2012. Girls Like Us. New York: Harper Collins.

Lawhorn, Joshlyn. 2018. "Race and Gender in (Re)integration of VictimSurvivors of CSEC in a Community Advocacy Context." Graduate Theses and Dissertations. https://scholarcommons.usf.edu/etd/7324

Lutnick, Alexandra. 2016. Domestic Minor Sex Trafficking: Beyond Victims and Villains. New York: Columbia University Press.

Mac, Juno and Molly Smith. 2018. Revolting Prostitutes: The Fight for Sex Workers Rights. New York: Verso Books.

“Mann Act.” n.d. Accessed February 26, 2019. http://law.jrank.org/pages/8420/MannAct.html.

Marshall, Nicky. 2012. "Michel Foucault: Disciplinary Power: Panopticism.” Michel Foucault (blog). September 4, 2012. https://michelfoucaultotago.blogspot.com/2012/09/panopticism.html.

Mitchell, K.J., Finkelhor, D., \& Wolak, J. 2010. Conceptualizing juvenile prostitution as child maltreatment: Findings from the National Juvenile Prostitution Study. Child Maltreatment, 15(1), 18-36.

McCoy, Kelli Ann. 2010. Claiming victims : the Mann Act, gender, and class in the American West, 1910-1930s. UC San Diego. ProQuest ID: McCoy_ucsd_0033D_11007.

Musto, Jennifer. 2016. Control and Protect: Collaboration, Carceral Protection, and Domestic Sex Trafficking in the United States. Oakland, California: University of California Press.

National Association of State Mental Health Program Directors (NASMHPD). 2013. National executive training institute curriculum for the creation of violence-free, coercion-free treatment settings and the reduction of seclusion and restraint (11th ed.). Alexandria, VA: Author.

Nikole Hannah-Jones. 2010. "Portland a Center for Human Trafficking, Officials Say." The Oregonian (Portland, OR), January 9, 2010, Sunrise edition. http://infoweb.newsbank.com/resources/doc/nb/news/12D2C355B8C395F0?p=N ewsBank. . 2011. "Story of 'Pornland' Is a Myth." The Oregonian (Portland, OR), January 14, 2011, Sunrise edition. 
http://infoweb.newsbank.com/resources/doc/nb/news/134C534C2D217B68?p=Ne wsBank.

Patton, Stacey. 2018. "Between a Rock and a Hard (to) Place: Raising Government Children: A History of Foster Care and the American Welfare State." The Women's Review of Books 35 (3): 10.

Platt, Anthony M. 1977. The Child Savers: The Invention of Delinquency. 2d ed., enl. A Phoenix Book. Chicago: University of Chicago Press.

Pleck, Elizabeth H. 1987. Domestic Tyranny: The Making of Social Policy against Family Violence from Colonial Times to the Present. New York: Oxford University Press.

Povinelli, Elizabeth A. 2001. "Radical Worlds: The Anthropology of Incommensurability and Inconceivability." Annual Review of Anthropology 30 (1): 319-34. https://doi.org/10.1146/annurev.anthro.30.1.319.

"President's Interagency Task Force to Monitor and Combat Trafficking in Persons." n.d. Accessed April 28, 2019. https://www.state.gov/j/tip/response/usg/index.htm.

Quiros, L., \& Berger, R. 2015. "Responding to the sociopolitical complexity of trauma: An integration of theory and practice." Journal of Loss and Trauma, 20, 149159.

Rakowski, Kyle. 2016. "Alienation and Identity Maintenance in Quasi-Total Institutions." Journal for Undergraduate Ethnography 6 (1): 17-31.

Reichert, J. and Sylwestrzak, A. 2013. "National survey of residential programs for victims of sex trafficking." Chicago, IL: The Illinois Criminal Justice Information Authority.

Ringdal, Nils J. 2004. Love for Sale: A World History of Prostitution. New York: Grove Press.

Rymph, Catherine E. 2012. "From 'Economic Want' to 'Family Pathology': Foster Family Care, the New Deal, and the Emergence of a Public Child Welfare System." Journal of Policy History 24 (01): 7-25. https://doi.org/10.1017/S0898030611000352.

Substance Abuse and Mental Health Services Administration. 2014. "Trauma-Informed Care in Behavioral Health Services. Treatment Improvement Protocol (TIP) Series 57." HHS Publication No. (SMA) 13-4801. Rockville, MD: Substance Abuse and Mental Health Services Administration. 
Scarry, Elaine. 1987. The body in pain: the making and unmaking of the world. New York: Oxford University Press.

Scheper-Hughes, Nancy, ed. 2004. Violence in War and Peace: An Anthology. Nachdr. Blackwell Readers in Anthropology 5. Malden, Mass.: Blackwell Publ. .2004. Introduction: Making sense of violence, in Violence in war and peace: An anthology. Edited by N. ScheperHughes and P. Bourgois, pp. 127. Oxford: Blackwell.

Shaw, Martin. 2019. The Night Wages. Devon, England: Cista Mystica Press.

Shepard, Katie. 2017. "A Portland Shelter Meant to Help Sexually Trafficked Teenagers Instead Drove Them Into the Street.” Willamette Week. December 6, 2017. http://www.wweek.com/news/2017/12/06/a-portland-shelter-meant-to-helpsexually-trafficked-teenagers-instead-drove-them-into-the-street/.

Siegel, Daniel J. 2001. "Toward an Interpersonal Neurobiology of the Developing Mind: Attachment Relationships, 'Mindsight,' and Neural Integration." Infant Mental Health Journal 22 (1 $\square 2)$ : 67-94. https://doi.org/10.1002/10970355(200101/04)22:1<67::AID-IMHJ3>3.0.CO;2-G.

Solomon, Marion Fried, and Daniel J Siegel. 2003. Healing Trauma: Attachment, Mind, Body, and Brain. https://www.overdrive.com/search?q=AAC44EEC-BC97-4457A1FF-3AC4F29E1DA8.

Sontag, Susan. 2003. Regarding the pain of others. New York: Farrar, Straus and Giroux.

The Sheela Na Gig Project - Researching Sheela Na Gig Sculptures in the UK. http://www.sheelanagig.org/wordpress/

"United Nations Convention against Transnational Organized Crime." n.d. Accessed February 25, 2019. https://www.unodc.org/unodc/en/organizedcrime/intro/UNTOC.html.

Vance, C. S. 2011. "Thinking Trafficking, Thinking Sex." GLQ: A Journal of Lesbian and Gay Studies 17 (1): 135-43. https://doi.org/10.1215/10642684-2010-024. . 2012. "Innocence and Experience: Melodramatic Narratives of Sex Trafficking and Their Consequences for Law and Policy." History of the Present 2, no. 2: 200-18.

Weller, Francis. 2015. The Wild Edge of Sorrow. Berkeley: North Atlantic Books.

Williams, L.M. and Frederick, ME. 2009. "Pathways into and out of commercial sexual victimization of children: Understanding and responding to sexually exploited teens." Lowell, MA. 
Wise, Tim J. 2012. Dear White America: Letter to a New Minority. San Francisco: City Lights Books.

Zizek, Slavoj. 2008. Violence: Six Sideways Reflections. 1st Picador ed. Big Ideas/Small Books. New York: Picador.

Zur, Judith. 1994. “The Psychological Impact of Impunity.” Anthropology Today 10 (3): 12. https://doi.org/10.2307/2783479. 


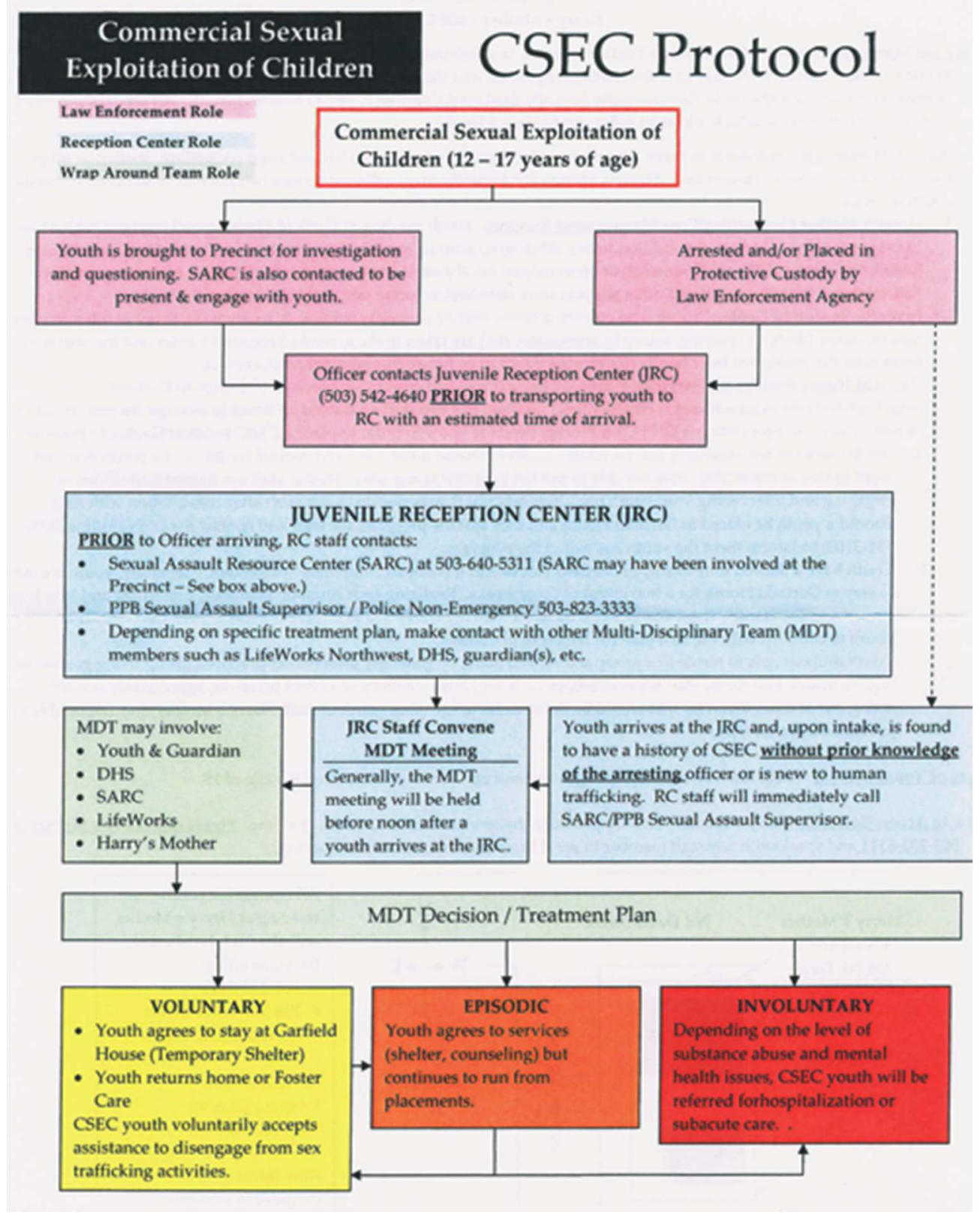

